\title{
\begin{tabular}{l|l} 
Mitraries & DSpace@MIT
\end{tabular}
}

\author{
MIT Open Access Articles
}

\section{The Mechanical Response of a Magma Chamber With Poroviscoelastic Crystal Mush}

The MIT Faculty has made this article openly available. Please share how this access benefits you. Your story matters.

Citation: Liao, Y., Soule, S. A., Jones, M., \& Le Mével, H. (2021). The mechanical response of a magma chamber with poroviscoelastic crystal mush. Journal of Geophysical Research: Solid Earth, 126, e2020JB019395.

As Published: http://dx.doi.org/10.1029/2020jb019395

Publisher: American Geophysical Union (AGU)

Persistent URL: https://hdl.handle.net/1721.1/140380

Version: Author's final manuscript: final author's manuscript post peer review, without publisher's formatting or copy editing

Terms of Use: Article is made available in accordance with the publisher's policy and may be subject to US copyright law. Please refer to the publisher's site for terms of use. 


\title{
The mechanical response of a magma chamber with poroviscoelastic crystal mush
}

\author{
Yang Liao $^{1}$, S. Adam Soule ${ }^{1}$, Meghan Jones ${ }^{1,2}$, Hélène Le Mével ${ }^{3}$ \\ ${ }^{1}$ Woods Hole Oceanographic Institution, Woods Hole, MA, USA \\ ${ }^{2}$ MIT/WHOI Joint Program in Oceanography, Woods Hole, MA, USA \\ ${ }^{3}$ Earth and Planets Laboratory, Carnegie Institution for Science, Washington DC, USA
}

\section{Key Points:}

- Features of magma chamber deformation with poroviscoealstic crystal mush are examined using a mechanical model

- Coexistence of poroelastic diffusion and viscoelastic relaxation causes non-monotonous evolution in pressure, stress, and magma transport

- The evolution of magma chamber is described by two characteristic time scales depending on the material properties 


\begin{abstract}
Improved understanding of the impact of crystal mush rheology on the response of magma chambers to magmatic events is critical for better understanding crustal igneous systems with abundant crystals. In this study, we extend an earlier model by Liao et al. (2018) which considers the mechanical response of a magma chamber with poroelastic crystal mush, by including poroviscoelastic rheology of crystal mush. We find that the coexistence of the two mechanisms of poroelastic diffusion and viscoelastic relaxation causes the magma chamber to react to a magma injection event with more complex time-dependent behaviors. Specifically, we find that the system's short-term evolution is dominated by the poroelastic diffusion process, while its long-term evolution is dominated by the viscoelastic relaxation process. We identify two post-injection timescales that represent these two stages and examine their relation to the material properties of the system. We find that better constraints on the poroelastic diffusion time are more important for the potential interpretation of surface deformation using the model.
\end{abstract}

\title{
1 Background: magma chamber model with poroelastic/viscoelastic mush
}

Petrological studies and thermodynamic models have long indicated that crustal magmatic reservoirs (i.e., magma chambers) contain an abundance of crystal mush, where 'mush' refers to a system with melt contained in a framework of crystals (Cashman et al., 2017; Marsh, 1989, 2013; Pritchard et al., 2018; Wieser et al., 2020). Crystals have thermal and geochemical importance, as they can alter the chemistry and thermal state of magma, and provide constrains on the thermal state and timescales of magma storage, ascent, and eruption (Costa et al., 2020; Antonelli et al., 2019; Cooper, 2019; Rummel et al., 2020; Sparks \& Cashman, 2017; Bachmann \& Huber, 2016; Singer et al., 2018). In recent decades, many research efforts have been devoted to understanding how crystal mush evolves and interacts with magma, using quantitative models and principles in thermodynamics, geochemistry, and geophysics. These models show that crystal mush is also important for various mechanical processes, such as magma segregation, gas filter pressing, and eruption onset via mush rejuvenation (Bachmann \& Bergantz, 2006; Huber et al., 2011; Sparks \& Cashman, 2017; Lamy-Chappuis et al., 2020; Spera \& Bohrson, 2018). Typically, crystal mush is treated in one of two ways in these quantitative models, either as a discrete granular system where grain-to-grain interaction is counted, or as a continuous system where the connected crystalline framework is treated as a viscous fluid or elastic solid (McKenzie, 2011; Gudmundsson, 2016; Liao et al., 2018; Schleicher \& Bergantz, 2017; Carrara et al., 2019). Most of these works focus on crystal mush in open magmatic reservoirs, while only a few studies focus on closed-system magma chamber models and the consequential ground deformation. Typically, these closed-system models invoke elasticity of the crystalline framework, making the mush material poroelastic, which conveniently allow prediction of deformation of the crust and surface (Gudmundsson, 2012; Liao et al., 2018). In a recent study, Liao et al. (2018) demonstrated that poroelastic crystal mush can significantly alter the response of a mushy chamber in its pressurization and stress development. Realistically, the rheology of crystal mush, when treated using continuum mechanics, is most likely to be both elastic and viscous, as it resides between the viscous (i.e., crystal suspension) and elastic (i.e., rock) end members (Aharonov \& Sparks, 1999). Although connecting crystals form a rigid, elastic framework, the crystals may slide past each other under stress, causing the matrix to viscously relax. The coexistence of both elastic and viscous deformation when a magma chamber experiences pressurization could cause unique geodetic signatures, such as distinct or multiple timescales or non-monotonous changes in ground deformation. Here, we expand Liao et al. (2018) to incorporate a more complete rheology including both elastic and viscous response of the crystal mush. We subject the magma chamber to a magma injection event and observe the effects of mush rheology on the response of the chamber in its pressurization, associated ground deformation, and timescales. As magma chamber deformation mod- 


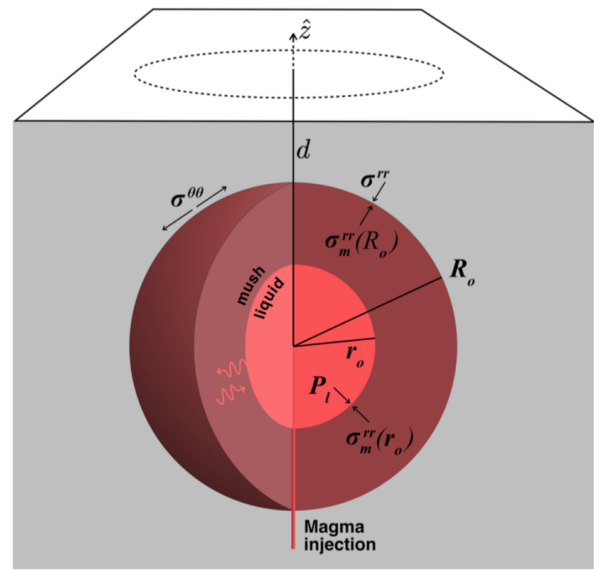

(a)

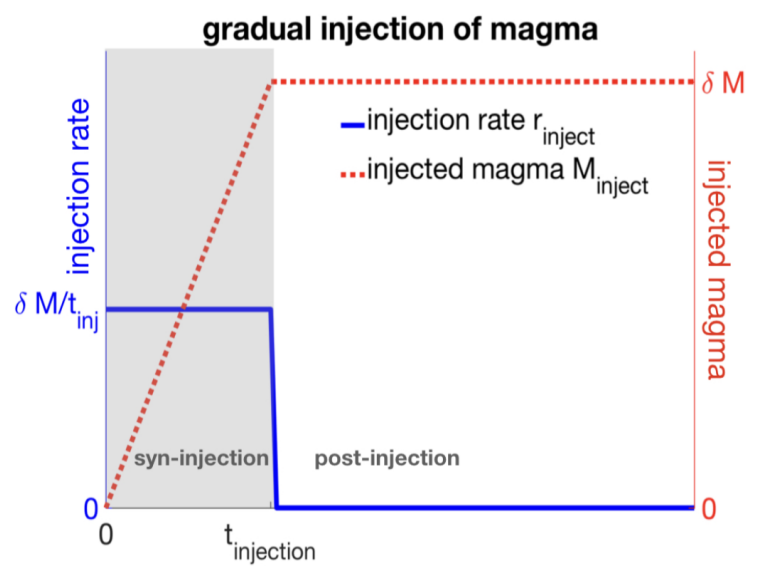

(b)

Figure 1. (a) Geometry of the mushy magma chamber model The magma chamber contains a fluid magma core (bright red) and poroviscoelastic mush (dark red), situated in an elastic crust (grey). The cartoon is adapted from (Liao et al., 2018), with several important quantities marked including: core pressure $P_{l}$, pore pressure $P_{f}$, tensile stress $\sigma^{\theta \theta}$, force balance on the two interfaces, and transport of magma in the mush region (red curved arrows). The chamber is at depth $d$ from a free surface with radius $R_{o}$ and liquid core radius $r_{o}$. (b)Accumulated amount of injected magma $M_{\text {inject }}$ (y axis on the right) and injection rate $r_{\text {inject }}$ (y axis on the left) as functions of time, $t_{i n j}$ is the length of the injection. The shaded area indicates the syn-injection period $0 \leq t \leq t_{i n j}$.

els are needed for geodetic inversion, conclusions from our study could yield insights on the interpretation of geodetic data caused by magma chamber deformation.

\section{Magma chamber model with poroviscoelastic mush in a half-space}

Our model is built on several assumptions which simplify the problem and allow for analytical solutions. For ease of comparison with previous mechanical magma chamber studies, we assume a spherical magma chamber and radial symmetry of mush distribution (Dragoni \& Magnanensi, 1989; Karlstrom et al., 2010; McTigue, 1987; Segall, 2016; Liao et al., 2018, e.g.,). There are multiple choices for a mush rheology that display both elastic and viscous features, and here we apply the classical linear poroviscoelasticty (Biot, 1962; Cheng, 2016) for analytical convenience. For simplicity, we consider the crystalinity/porosity and material properties to be uniform across the shell, and constant through time. In this model we consider only mechanical processes, hence thermodynamic processes such as dissolution/crystallization and volatile exsolution are neglected. Thus, our model is a simplification that can nevertheless provide useful insights into the behavior of mushy magmatic systems, and more refinements would be required in future studies to develop models suitable for simulating realistic volcanic systems.

The magma chamber chamber consists of a three-dimensional spherical core of liquid magma within a shell of crystal mush. The magma chamber is hosted in a half space of linear elastic crust with a traction-free upper surface. We approximate the surface deformation in vertical and horizontal directions following the same approach used in earlier studies (Segall, 2016, 2019; McTigue, 1987). 
We assume a simplified magma injection event, where magma enters into the liquid core at a constant injection rate during the injection period $0 \leq t \leq t_{\text {inj }}$ (Figure 1b), leading to the accumulated mass of injected magma $M_{i n j e c t}=\frac{t \delta \bar{M}}{t_{i n j}}$ for $t \leq t_{i n j}$ and $M_{\text {inject }}=\delta M$ for $t>t_{\text {inj }}$.

During and after the injection, magma is allowed to flow across the liquid-mush interface and within the mush, driven by the gradient of pore pressure $P_{f}$. The motion of pore magma follows Darcy's law and mass conservation

$$
\begin{aligned}
& \vec{q}=-\frac{\kappa}{\eta_{f}} \nabla P_{f} \\
& \frac{\partial m}{\partial t}+\nabla \cdot\left(\rho_{f} \vec{q}\right)=0
\end{aligned}
$$

where $\vec{q}$ is the Darcy velocity (positive values indicates the flow direction from magma core to the chamber wall), $\kappa$ is the permeability of the mush, $\eta_{f}$ is the magma viscosity, and $\rho_{f}$ is the density of pore magma. The variation in fluid content is described by the function $m(r, t)$, which is defined as the change in pore fluid mass per un-deformed volume of mush located at radius $r$ (positive value $m>0$ indicates that the pores in the mush gain magma). The integration of $m$ across the mush shell leads to the total amount of magma transported between the liquid and the mushy region

$$
M_{l e a k}=\int_{r_{o}}^{R_{o}} 4 \pi r^{2} m(r, t) \mathrm{d} r
$$

where $M_{\text {leak }}(t)$ is the accumulated amount of magma transported across the magma-mush boundary. $M_{\text {leak }}>0$ indicates that magma is flowing from the liquid core to the mushy shell (i.e., 'leaking'). We calculate the pressure change $P_{l}$ in the liquid core upon mass injection assuming isothermal compression, which depends on the amount of injected magma $M_{\text {inject }}$, the amount of magma exchanged between the core and mush $M_{\text {leak }}$, and the volume change of the liquid core indicated by the radial displacement $u_{m}\left(r_{o}\right)$ on the coremush interface. After linearization, the pressure change is (Liao et al., 2018):

$$
P_{l}(t)=K_{l}\left(\frac{M_{i n j}(t)}{M_{o}}-\frac{M_{l e a k}(t)}{M_{o}}\right)\left(1-3 \frac{u_{m}\left(r_{o}, t\right)}{r_{o}}\right)
$$

where $K_{l}$ is the bulk modulus (1/compressibility) of the core and injected magma, and $M_{o}$ is the pre-injection magma mass in the liquid core (see Appendix A). The injection causes the chamber to inflate, which leads to increased displacement $\vec{u}_{\text {rock }}$ and elastic stress $\boldsymbol{\sigma}_{\text {rock }}$ in the surrounding crustal rocks, following the constitutive relation for linear elastic material

$$
\boldsymbol{\sigma}_{\text {rock }}=\left(K_{r}-\frac{2}{3} \mu_{r}\right) \nabla \cdot \vec{u}_{\text {rock }} \boldsymbol{I}+\mu_{r}\left(\nabla \vec{u}_{\text {rock }}+\nabla \vec{u}_{\text {rock }}^{T}\right)
$$

where $K_{r}$ and $\mu_{r}$ are the bulk and shear modulus of the host rock, respectively. It is worth noting that both the stress component in the tensile direction $\sigma^{\theta \theta}$ on the chamber-rock boundary (Figure 1a) and overpressure increase during the inflation of the chamber, which may cause the chamber's wall to rupture (Pinel \& Jaupart, 2003; Grosfils, 2007; Currenti \& Williams, 2014; Albino et al., 2010; Karlstrom et al., 2010; Gudmundsson, 2012; Zhan \& Gregg, 2019; Gerbault et al., 2018). In our current model, the rupture of magma chamber is omitted. To capture both the elastic and viscous aspects of the crystaline framework in the crystal mush, we apply a linear poroviscoelastic rheology. The constitutive relations we invoke here are equivalent to the ones developed by Biot (1962), which combine linear poroelasticity with a Maxwell viscoelastic relaxation model. The strain $\boldsymbol{\epsilon}_{m}$, stress $\boldsymbol{\sigma}_{m}$, variation in fluid content $m$ and pore pressure $P_{f}$ obey the constitutive relations 


$$
\begin{aligned}
& \left(\frac{\partial \boldsymbol{\sigma}_{m}}{\partial t}+\frac{\mu_{m}}{\eta_{m}} \boldsymbol{\sigma}_{m}\right)-\frac{1}{3} \frac{\mu_{m}}{\eta_{m}} \operatorname{Tr}\left(\boldsymbol{\sigma}_{m}\right) \mathrm{I}=2 \mu_{m} \frac{\partial \boldsymbol{\epsilon}_{m}}{\partial t}+\left(K_{m}-\frac{2}{3} \mu_{m}\right) \frac{\partial \operatorname{Tr}\left(\boldsymbol{\epsilon}_{m}\right)}{\partial t} \mathrm{I}-\alpha \frac{\partial P_{f}}{\partial t} \mathrm{I} \\
& m=\rho_{f} \alpha\left(\operatorname{Tr}\left(\boldsymbol{\epsilon}_{m}\right)+\frac{\alpha}{K_{u}-K_{m}} P_{f}\right)
\end{aligned}
$$

where $K_{m}$ is the drained modulus (i.e., the bulk modulus of the crystalline framework), and $K_{u}$ is the is the undrained modulus (i.e., bulk modulus of the whole crystal-fluid ensemble). $\alpha$ is the poroelastic constant (also known as Biot constant) with a value from 0 to 1 , determined by the strength of the crystalline framework relative to that of the single crystal (represented by its bulk modulus $K_{s}$ ) as $\alpha=1-\frac{K_{m}}{K_{s}}$. We assume that the crystalline network itself is weak compared to the single crystals, thus $K_{m}<<K_{s}$, leading to a large $\alpha$. We use $\alpha=0.9$ for the rest of the study which is chosen based on the likely slit-shaped pores in the crystal mush, which are expected to cause an alpha that is large but less than unity. This value is consistent with experimental results (Makhnenko \& Labuz, 2016; Liao et al., 2018). The viscoelastic relaxation of the crystalline matrix is determined by its rigidity $\mu_{m}$ and shear viscosity $\eta_{m}$. We can verify that the poroelastic and viscoelastic rheologies are two end members of the poroviscoelastic rheology: when matrix viscosity $\eta_{m} \rightarrow \infty$, (5) reduces to linear poroelasticity (Biot, 1941; Cheng, 2016); when pore pressure is decoupled from the stress (i.e., $\alpha=0)$, (5) becomes the classical Maxwell formulation (Segall, 2016; Jellinek \& DePaolo, 2003). In the model, we assume that the viscous relaxation of the mush network primarily occurs in the shear component (i.e., infinite bulk viscosity), hence omitting the compaction effect. The deformation in the host rocks and the mush shell obey quasi-equilibrium condition

$$
\nabla \cdot \boldsymbol{\sigma}_{m, \text { rock }}=0
$$

and boundary conditions,

$$
\begin{aligned}
P_{l}+\sigma_{m}^{r r}\left(r_{o}\right) & =0 \\
P_{l}-P_{f}\left(r_{o}\right) & =0 \\
\sigma_{m}^{r r}\left(R_{o}\right)-\sigma_{\text {rock }}^{r r}\left(R_{o}\right) & =0 \\
\vec{u}_{m}\left(R_{o}\right)-\vec{u}_{\text {rock }}\left(R_{o}\right) & =0 \\
\frac{\partial P_{f}}{\partial r}\left(R_{o}\right) & =0 \\
u_{\text {rock }}(r \rightarrow \infty) & =0
\end{aligned}
$$

which prescribes force balance, continuity (in displacement and fluid pressure) at both the magma-mush and mush-rock boundaries, and a chamber wall impermeable to the pore magma. The above constraints determine the unique time-dependent solutions, which are calculated using Laplace transform (see Appendix A). We follow earlier studies to approximate the surface deformation resulting from the deformation of a spherical chamber (McTigue, 1987; Segall, 2016, 2019)

$$
\begin{aligned}
& u_{z}(\rho, t)=-\frac{\sigma_{m}^{r r}\left(R_{0}, t\right)}{\mu_{r}} \frac{R_{0}^{3}}{d^{2}} \frac{1-\nu}{\left(\frac{\rho^{2}}{d^{2}}+1\right)^{\frac{3}{2}}} \\
& u_{\rho}(\rho, t)=-\frac{\sigma_{m}^{r r}\left(R_{0}, t\right)}{\mu_{r}} \frac{R_{0}^{3}}{d^{2}} \frac{1-\nu}{\left(\frac{\rho^{2}}{d^{2}}+1\right)^{\frac{3}{2}}} \frac{\rho}{d}
\end{aligned}
$$

where $u_{z}$ and $u_{\rho}$ are the vertical and horizontal displacement on the surface $z=0$, measured at a radial distance $\rho ; \nu$ is the Poisson's ratio of the elastic crust, $\sigma_{m}^{r r}$ is the radial 
component of stress at the chamber-crust interface. Earlier works demonstrated that when the depth of the magma chamber $d$ is modestly larger than the chamber's radius $d / R_{0} \geq$ 2, (8) provides good estimations for the deformation on the surface (Segall, 2016). In our study, we assume $d / R_{0}$ between 3 to 10 for precise approximation of the ground deformation. Because the poroviscoelastic mush is subjected to two different mechanisms (poroelastic diffusion and viscoelastic relaxation), we identify two timescales that represent the two mechanisms respectively (see Appendix A)

$$
\begin{aligned}
\tau_{\text {diffusion }} & =\frac{R_{o}^{2} \eta_{f}}{\kappa} \frac{\alpha^{2}\left(K_{u}+\frac{4}{3} \mu_{m}\right)}{\left(K_{u}-K_{m}\right)\left(K_{m}+\frac{4}{3} \mu_{m}\right)} \\
\tau_{\text {relaxation }} & =\frac{\eta_{m}}{\mu_{m}}
\end{aligned}
$$

where $\tau_{\text {diffusion }}$ is the poroelastic diffusion time and $\tau_{\text {relaxation }}$ is the viscoelastic relaxation time. We verify that the crystal mush is poroelastic when $\tau_{\text {relaxation }}=\infty$, and viscoelastic if $\tau_{\text {diffusion }}=\infty$. Given the uncertainties in parameters such as mush permeability, crystalline rigidity and viscosity, magma viscosity and compressibility, $\tau_{\text {relaxation }}$ and $\tau_{\text {diffusion }}$ can have a wide range of values. For example, the poroelastic diffusion time $\tau_{\text {diffusion }}$ ranges from 6 days to 160 years assuming a magma chamber with $1 \mathrm{~km}$ radius and parameters similar to those used in other studies $\left(\alpha=0.9, \mu_{m}^{o}=1 \mathrm{GPa}\right.$, $K_{f}=1 \mathrm{GPa}, \kappa \in\left[10^{-10}, 10^{-8}\right] \mathrm{m}^{2}$, and $\eta_{f} \in\left[10^{1}, 10^{3}\right]$ Pa.s) (Shaw et al., 1968; Schmeling, 1985; Schmeling et al., 2012; Makhnenko \& Labuz, 2016; Liao et al., 2018). Further, assuming a crystalline viscosity similar or smaller than heated rock $\left(\eta_{m} \in\left[10^{16}, 10^{18}\right]\right.$ Pa.s), the resulting viscoelastic relaxation time $\tau_{\text {relaxation }}$ ranges from 4 months to 30 years (Segall, 2016; Cheadle et al., 2004; McKenzie, 2011). Below, we choose the case of a poroviscoelastic mush subjected to both mechanisms with comparable time scales $\tau_{\text {diffusion }}=\tau_{\text {relaxation }}$ to illustrate the basic features of a poroviscoelastic mushy chamber.

It is worth noting that, although the current model fills the gap in rheology assumed in Liao et al. (2018), many assumptions are still made to simplify the problem. These assumptions, including the spherical geometry, radial symmetry in magma chamber deformation, homogeneity in crystal mush distribution, neglected thermal effects and matrix compaction under finite bulk viscosity could all affect how a more realistic mushy magma chamber reacts to magma injection, and, while beyond the scope of this study, should be examined and evaluated in future studies.

\section{Model results}

For ease of comparison, the parameters we use in the current study are similar to those used in (Liao et al., 2018). We show the dimensionless analytical solutions normalized by the length scale $R_{o}$ (chamber radius) and stress scale $\mu_{r}$ (shear modulus of hosting rock). Similar to poroelastic or viscoelastic mush, the poroviscoelastic mush causes the magma chamber and its surrounding crust to continue evolving after the injection has stopped, as opposed to a fluid chamber that reaches steady state as soon as the injection ends (Figure 4). We find that the time-dependent evolution of the poroviscoelastic mushy chamber is, at different times, dominated by either poroelastic diffusion or viscoelastic relaxation. Except for the case of very long injection time, the qualitative behaviors of the chamber are robust for a wide range of material properties (see section 3.2). Below, we examine the features of deformation, pressure, stress, and magma transport in both stages.

\subsection{Syn- and post- injection evolution of magma chamber with poro- viscoelastic mush shell}

We examine time-dependent magma chamber deformation during three stages: syninjection, shortly after the injection, and long the after the injection. During the syn- 


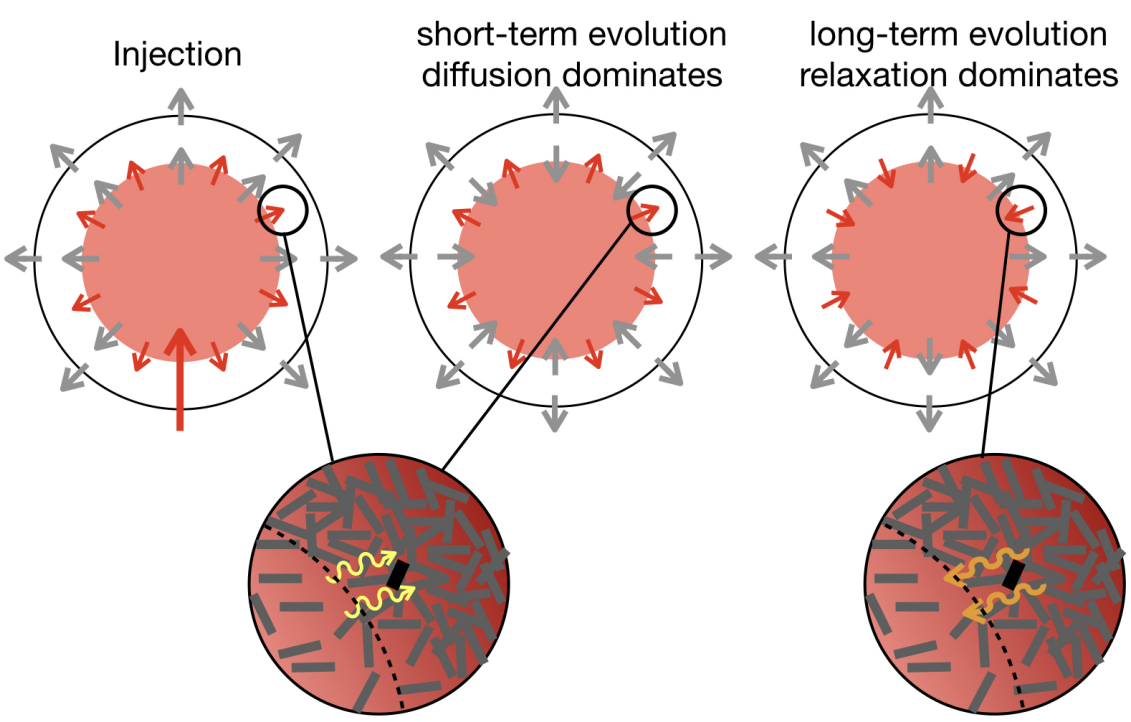

Figure 2. Cartoon illustration of the three stages in the dynamic evolution of a mushy magma chamber: syn-injection stage, poroelastic diffusion-dominated stage, and viscoelastic relaxation-dominated stage. Grey arrows indicate the direction of the radial displacement of the magma-mush and mush-rock boundaries, and red arrows show the direction of magma transport. Illustration of pore magma transport and their possible chemical signatures are shown in the zoom-in panels. The deformation dominated by poroelastic diffusion is consistent with the evolution shown in Figure 3(b), and the viscous relaxation-dominated regime is consistent with Figure 3(c).

injection period, magma is added into the liquid core at a constant rate (shaded area in Figure 1b), increasing the pressure in the core magma (Figure 4a), and pushing both the magma-mush boundary at $r=r_{o}$ and the mush-rock boundary at $r=R_{o}$ outward (Figure 3a). The expansion of the whole chamber causes the tensile stress in the rock surrounding the chamber and ground deformation to increase with time (Figure 4b, Figure 8a). During the syn-injection period, pressure in the liquid core always exceeds the pore pressure in the mush shell. As a result, some magma in the liquid core flows into the mush (Figure 5a), increasing the pore pressure in the mush (See Figure B2 in Appendix B). The syn-injection period ends at $t=t_{i n j}$, when the injection rate drops to 0 . At the end of the injection, a fluid pressure gradient remains that sustains magma flow from the core fluid into the mush.

The short post-injection period begins when the injection stops, at $t=t_{i n j}$. Without more magma injection, the fluid core loses magma due to porous flow into the mush, causing the pressure in the liquid core to decrease. The liquid-mush boundary retracts inward and the liquid core shrinks in response to the decreasing core pressure and mush expansion (Figure 5b, Figure 4a, Figure 3b). This feature is similar to that of a chamber with poroelastic mush (see Figure 3b in Liao et al. (2018)). Although viscous relaxation also occurs during this period, it is not strong enough to noticeably deviate the evolution of the system from that of a poroelastic chamber. Because of these qualitative similarities, we consider the short time period post-injection evolution to be dominated by the poroelastic diffusion mechanism (middle panel in Figure 2). 


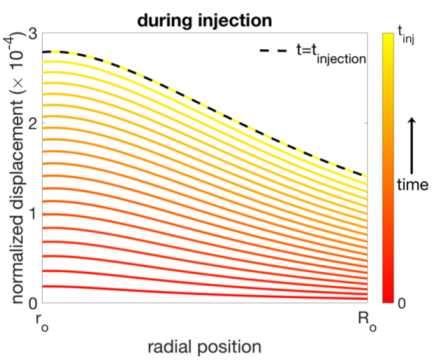

(a)

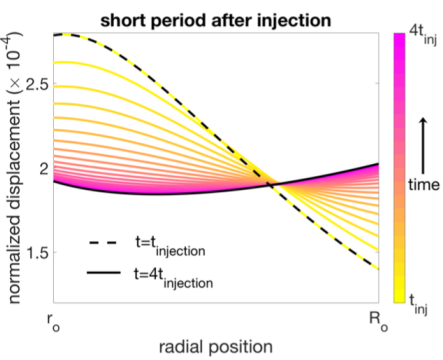

(b)

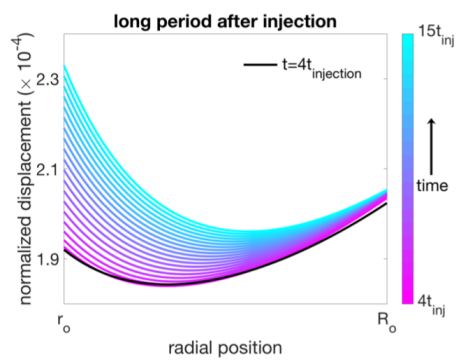

(c)

Figure 3. Displacement in the poroviscoelastic mush shell during and after injection. The thickness of the mush shell is half of the total chamber radius $\left(r_{o}=R_{o} / 2\right)$ with equal relaxation and diffusion times $\tau_{\text {relaxation }}=\tau_{\text {diffusion }}$. A total amount of magma $\delta M=0.02 M_{o}$ is injected for the duration of $t_{\text {injection }}=\tau_{\text {diffusion }} / 10$. Left panel shows the displacement $u(r) / R_{o}$ (normalized by the chamber radius) as a function of radial position $r$ during the injection $0 \leq t \leq t_{\text {injection, }}$, where the black dash line indicates the displacement profile at the end of the injection $t=t_{\text {injection }}$; middle panel shows the displacement during a short time period after the injection $t_{\text {injection }} \leq t \leq 4 t_{\text {injection, }}$, where the black dash line and black solid line show the profile at $t=t_{\text {injection }}$ and $t=4 t_{\text {injection }}$, respectively; right panel shows the displacement for longer period after the injection $t>4 t_{\text {injection, }}$, where the black solid line indicates the profile at $t=4 t_{\text {injection. }}$. The left and middle panels are qualitatively similar to the evolution of a poroelastic shell (see Figure 3 in Liao et al. (2018)). The poroelastic dominated and viscoelastic dominated deformations are also shown in cartoon illustration in Figure 2. Other parameters include $\alpha=0.9, r_{o} / R_{o}=1 / 2, K_{f} / \mu_{r}=0.5, K_{l} / \mu_{r}=0.1, K_{s} / \mu_{r}=5 / 3, \mu_{m} / \mu_{r}=1 / 2, \phi_{o}=0.2$.

With time, the effect of viscoelastic relaxation becomes more apparent - as the poroelastic effects diminish - and the system begins to show features similar to those displayed by a purely viscoelastic mushy chamber. During this period, the viscoelastic relaxation causes outward creeping and compression of the whole mush shell (Figure 3c), reversing the motion of the previously retracting liquid-mush boundary and pushing it outward again (Figure 2b). The outward movement of the liquid-mush boundary causes the volume of the liquid core to expand, and the pressure in it to further decrease (Figure 4a). The outward creeping of the mush-rock boundary causes the tensile stress in the host rock and ground deformation to continue increasing (Figure 4b, Figure 8a). Eventually, the liquid core pressure becomes less than the pore pressure in the adjacent mush due to the loss of core magma and the expansion of the core. This reverses the pressure gradient direction at the magma-mush boundary resulting in porous flow from the mush into the core (Figure 5c), returning most of the previously leaked magma back into the core at a slower speed (Figure 6). This stage, where the magma chamber is dominated by viscoelastic relaxation, lasts until the system reaches a new steady state. Although the decrease in chamber pressure and increase in tensile stress of the crust during this period are similar in sign to the poroelastic diffusion dominated stage, the rate of change in these quantities is much lower, as is reflected by a nearly indiscernible strain rate at the wall of the chamber (Figure B1 in Appendix Appendix B) and slow increase in ground elevation (Figure 8).

\subsection{Timescales in post-injection evolution}

Compared to the poroelastic case where one timescale can be identified to describe its post-injection evolution (Liao et al., 2018), a chamber with poroviscoealstic mush re- 


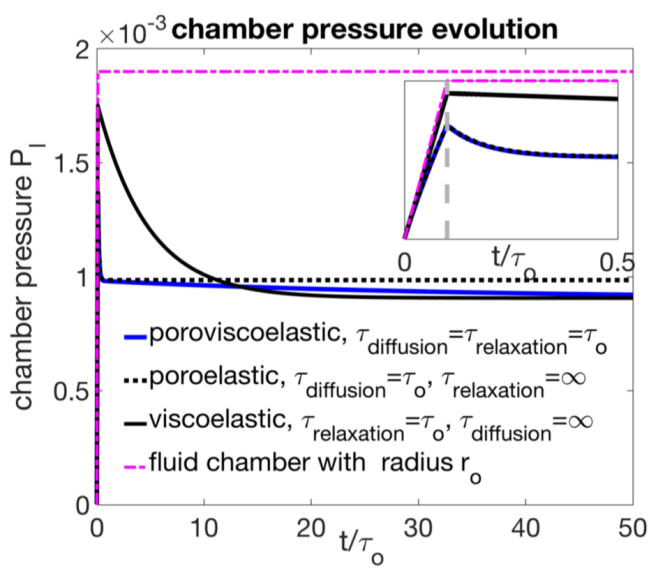

(a)

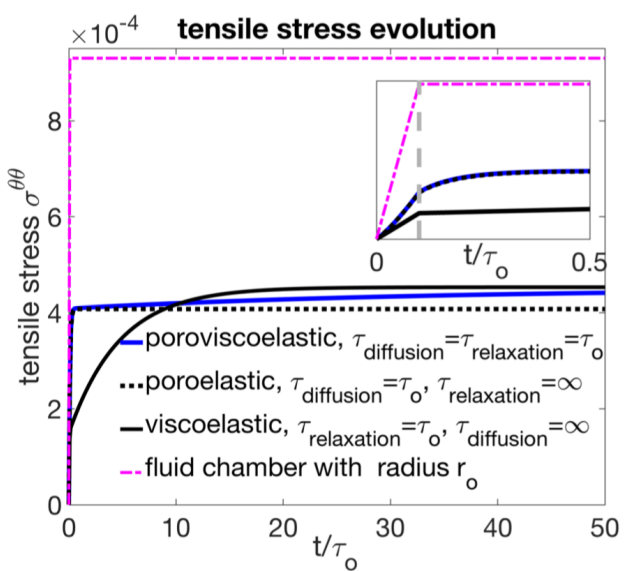

(b)

Figure 4. Syn- and post-injection evolution of liquid core fluid pressure $P_{l}$ (normalized, panel a), and tensile stress $\sigma^{\theta \theta}$ (normalized, panel b) as functions of time, with initial short period evolutions zoomed in insert panels. Purple broken line corresponds to a mushless liquid chamber with the mushy chamber's liquid core radius $r_{0}=0.5 R_{0}$; blue solid lines, black dotted lines, and black solid lines correspond to a mushy chamber with poroviscoelastic, poroelastic, or viscoelastic mush shell respectively. Other parameters are the same as in Figure 3. $\tau_{o}$ is an arbitrary scale for normalizing time and its actual value has no contribution to the result. The response of poroviscoelastic mush (blue line) is nearly identical to that of poroelastic mush (black dash line) in the short time period (zoom-in panel), and similar to that of a viscoelastic mush (black solid line) in the long time period. 


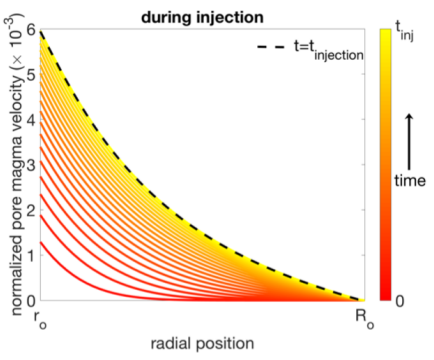

(a)

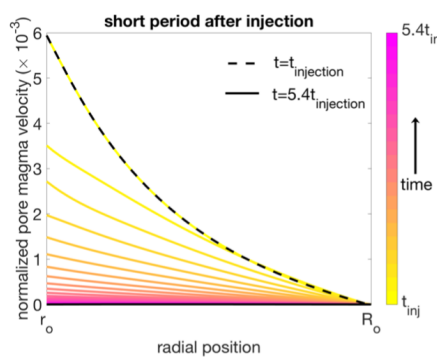

(b)

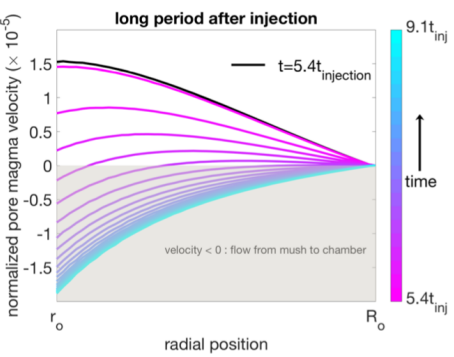

(c)

Figure 5. Darcy velocity of pore magma $\vec{q}$ (radial component) in the poroviscoelastic mush shell, as a function of radial position $r$, during and after injection. The thickness of the mush shell is half of the total chamber radius $\left(r_{o}=R_{o} / 2\right)$ with equal relaxation and diffusion time $\tau_{\text {relaxation }}=\tau_{\text {diffusion }}$. A total amount of magma $\delta M=0.02 M_{o}$ is injected for the duration of $t_{\text {injection }}=\tau_{\text {diffusion }} / 10$. The velocity is normalized by velocity scale $\kappa \mu_{r} / \eta_{f} R_{o}$, where $\kappa$ is the mush permeability, $\mu_{r}$ is the crustal rock rigidity, $\eta_{f}$ is the viscosity of pore magma, and $R_{o}$ the radius of the chamber. Positive values of $q$ indicate the magma flowing from the core to the mush, and negative values indicate flow from the mush into the core. Left panel corresponds to syn-injection evolution $0 \leq t \leq t_{\text {injection, }}$, where the black dash line indicates the velocity profile at the end of the injection $t=t_{\text {injection }}$; middle panel shows the pore magma velocity during a short time period after the injection $t_{\text {injection }} \leq t \leq 5.4 t_{\text {injection }}$, where the black dash line and black solid line show the profile at $t=t_{\text {injection }}$ and $t=5.4 t_{\text {injection }}$, respectively; right panel shows the velocity for longer period after the injection $t>5.4 t_{\text {injection }}$, where the black solid line indicates the profile at $t=5.4 t_{\text {injection }}$. The poroelastic dominated and viscoelastic dominated pore magma flow direction are also shown in cartoon illustration in Figure 2. The region where $q<0$ in the right panel indicates the change in flow direction of the pore magma, which corresponds to the onset of decrease in the amount of cumulated leaked magma (see Figure B2 in Appendix B for the amount of transported magma). Other parameters are the same as in Figure 3. 


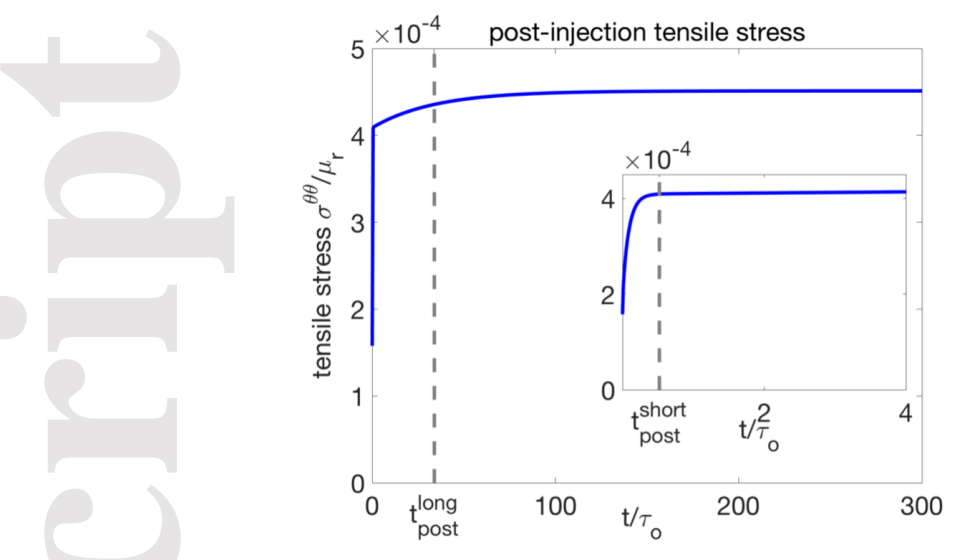

(a)

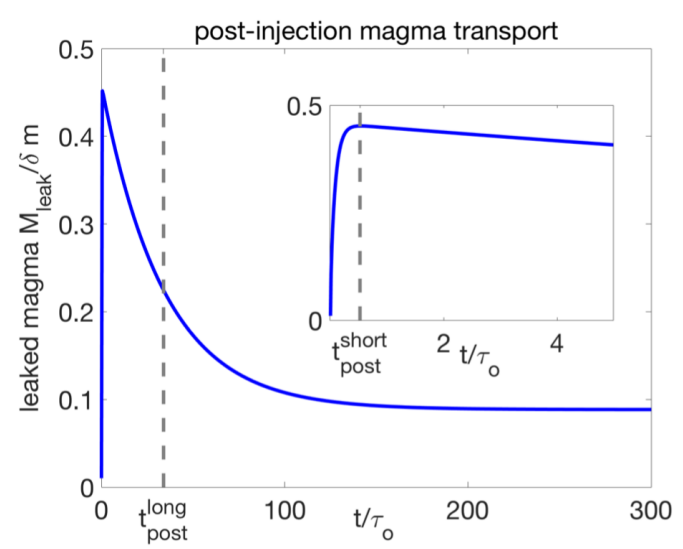

(b)

Figure 6. Post-injection short-term (insert panels) and long-term evolution of tensile stress (left) and leaked magma $M_{\text {leak }}$ (right) from the liquid core to the shell following a sudden injection. Grey dashed lines indicate the two post-injection timescales $t_{\text {post }}^{\text {long }}$ and $t_{\text {post }}^{\text {short }}$ identified for the post-injection evolution.

quires two timescales to characterize the non-monotonic changes in pressure, stress, and magma transport (Figure 4 and 6). To determine the short-period evolution time $t_{\text {post }}^{\text {short }}$, we numerically calculate the time it takes for the pressure gradient at the magma-mush interface to reverse, and for magma to begin to leak back into the liquid core (Figure 6b) after a sudden injection. To determine the long-period evolution time $t_{\text {post }}^{\text {long }}$, we calculate the time it takes for the system to approach a final steady state after injection. We obtain this time by examining the analytical solutions and choosing the longest exponential decay time. After $t_{\text {post }}^{\text {long }}$, all quantities in the system approach a steady state (see Appendix Appendix A and Liao et al. (2018)). Following a sudden injection at $t=0$, the evolution of the system during time period $0<t \leq t_{\text {post }}^{\text {short }}$ is consistent with a poroelastic diffusion dominated stage, represented by a relatively rapid decrease in chamber's pressure $P_{l}$, a rapid increase in tensile stress $\sigma^{\theta \theta}$, and core-to-mush magma transport. Over the time period $t_{\text {post }}^{\text {short }}<t \leq t_{\text {post }}^{\text {long }}$, the system behaves consistently with a viscoelastic relaxation dominated stage, characterized by a slower decrease in chamber's pressure, slow increase in tensile stress, and mush-to-core magma transport. Over the time period $t>t_{\text {post }}^{\text {long }}$, the system remains dominated by viscoelastic relaxation, although its evolution is slow enough to be regarded as approaching a new steady state.

We found that both $t_{\text {post }}^{\text {short }}$ and $t_{\text {post }}^{\text {long }}$ depend on the material properties (e.g., $\tau_{\text {diffusion }}$ and $\left.\tau_{\text {relaxation }}\right)$ and geometry of the system (e.g., $\left.r_{o} / R_{o}\right)$. Although $\tau_{\text {diffusion }}$ and $\tau_{\text {relaxation }}$ both affect $t_{\text {post }}^{\text {short }}$ and $t_{\text {post }}^{\text {long }}$, it is clear that the short-period evolution time $t_{\text {post }}^{\text {short }}$ is more sensitive to $\tau_{\text {diffusion }}$; whereas the long-period evolution time $t_{\text {post }}^{\text {long }}$ changes more sensitively with $\tau_{\text {relaxation }}$ (except when $\tau_{\text {diffusion }}$ is orders of magnitude larger than $\tau_{\text {relaxation }}$ ) (Figure 7). Considering that the early post-injection evolution of the system corresponds to faster change and higher strain-rate, we consider it to be potentially more relevant to geophysical observations (e.g., deformation, seismicity), hence constraining the value of $\tau_{\text {diffusion }}$ is important for comparing the model to field data. According to (9a), $\tau_{\text {diffusion }}$ is determined by parameters with potentially large degrees of uncertainty, such as the poorly constrained mush permeability $\kappa$, and the magma viscosity $\eta_{f}$, which has a wide range of values depending on temperature, degree of crystallization, and chemical compositions. Reasonable variations in these parameters can cause $\tau_{\text {diffusion }}$ to vary across orders of magnitudes from days to hundreds of years. For these reasons, better constraints on these parameters via petrological observations and thermodynamic models are cru- 


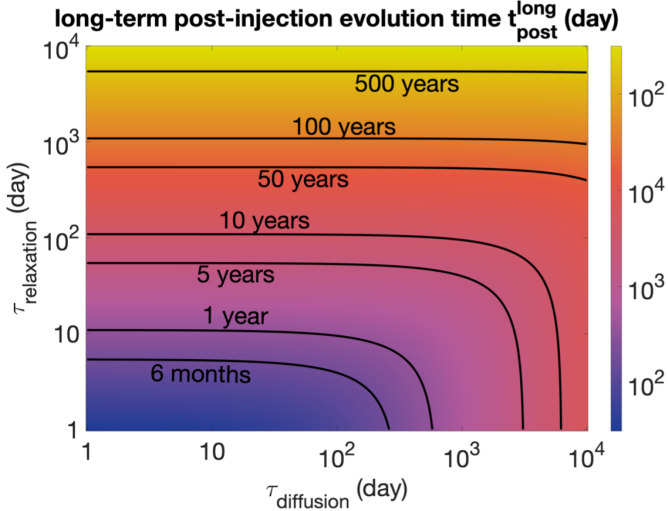

(a)

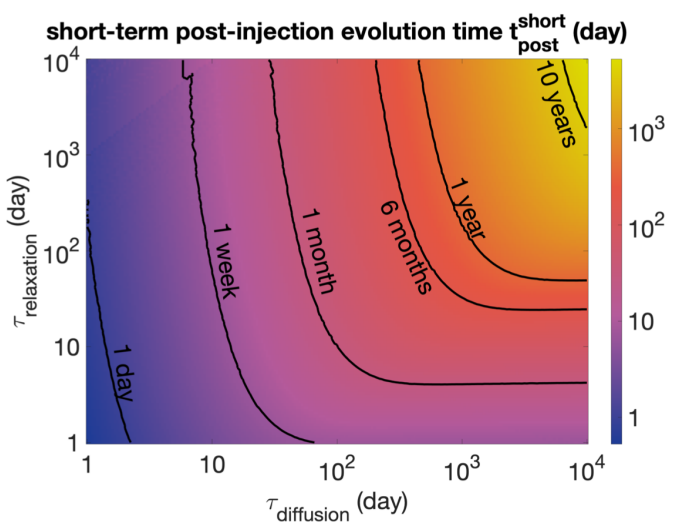

(b)

Figure 7. Post-injection short-term evolution timescale $t_{\text {post }}^{\text {short }}$ (right) and long-term evolution timescale $t_{\text {post }}^{\text {long }}$ (left) shown as functions of viscoelastic relaxation time $\tau_{\text {relaxation }}$ and poroelastic diffusion time $\tau_{\text {diffusion }}$ of a mushy magma chamber with $r_{o} / R_{o}=0.5$. The long-term evolution time $t_{\text {post }}^{\text {long }}$ is more sensitive to the change in viscoelastic relaxation time; the short-term evolution time is more sensitive to the change in poroelastic diffusion time.

cial for evaluating rheological models such as the one proposed here. It is also worth noting that the two post-injection timescales are defined based on the evolution of magma chamber following a sudden injection, and can qualitatively describe the behavior of a mushy chamber when the injection is much shorter than both $\tau_{\text {diffusion }}$ or $\tau_{\text {relaxation }}$. For very long injection times (i.e., low injection rates), however, the diffusion-dominated stage becomes very short, and the chamber would qualitatively display characteristics of the relaxation-dominated stage soon after the injection (see Figure B3 in Appendix Appendix B).

\section{Implications and future studies}

Our model allows to explore the consequences of magma injection in a chamber with a poroviscoelastic mush layer on some common observations made in magmatic systems. In this section we discuss two examples of implications of our model for geodesy and petrology. Although these predictions are highly generalized at this stage, they indicate the potential for future model development that incorporates more realistic and complex features of natural magmatic systems to provide novel ways to interpret volcano geophysical and petrological data.

\subsection{Implication on the interpretation of ground deformation}

One consequence of the existence of mush in a magma chamber is prolonged ground deformation after the injection has ceased due to redistribution of pore magma and/or relaxation of the crystalline framework. For example, a $1.5 \mathrm{~km}$ mushy magma chamber at $4.5 \mathrm{~km}$ depth undergoing a one-year injection with a moderate rate of $1.12 \mathrm{~m}^{3} / \mathrm{s}$ would cause an additional $30 \mathrm{~mm}$ of ground uplift ( $1 / 3$ of total uplift) over three years after the injection has stopped (Figure 8a), whereas a fluid-filled chamber under the same circumstances would cause no additional ground uplift once the injection has stopped (Le Mével et al., 2015). The time-dependent changes in the rate of ground deformation for a mushy chamber is also distinct from those for a liquid chamber hosted in elastic rock. Specifically, our mushy chamber model predicts an increasing syn-injection ground uplift rate, 


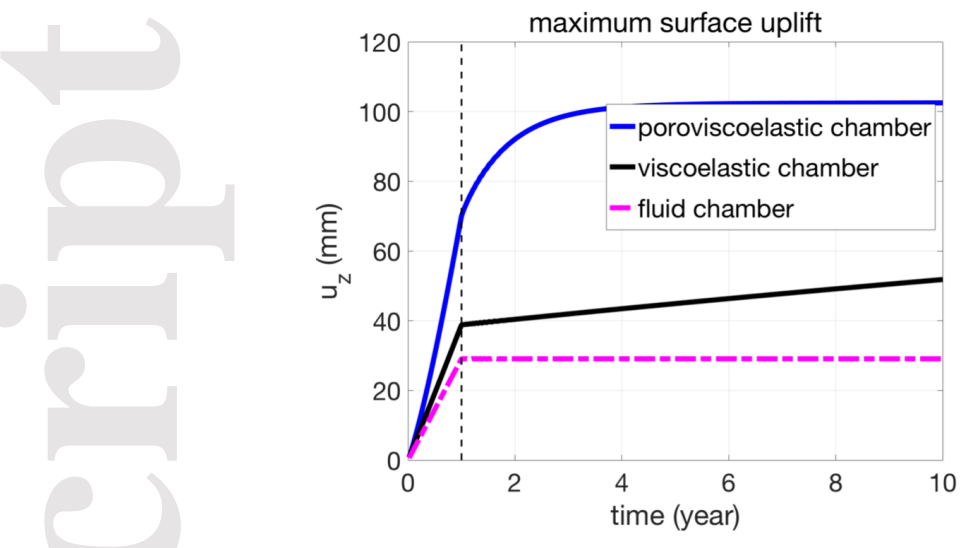

(a)

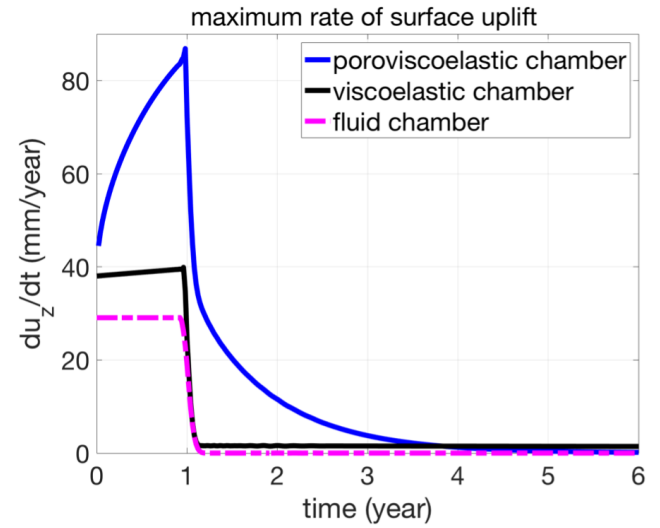

(b)

Figure 8. Vertical surface uplift (panel a) and rate of surface uplift (panel b) as functions of time during and after injection, for a liquid chamber (purple broken lines) and a mushy chamber with either poroviscoelastic (blue solid lines) or viscoelastic (black solid lines) mush (diffusion and/or relaxation time $\sim 10$ years). The center of the magma chamber is located at a depth of $4.5 \mathrm{~km}$, with a radius of $1.5 \mathrm{~km}$. The injection assumes a volumetric injection rate of $1.12 \mathrm{~m}^{3} / \mathrm{s}$ for the duration of 1 year, indicated by black dash line in panel a. The rate of ground deformation has been smoothed using a piece-wise, low-pass Butterworth filter to eliminate numerical artifacts caused by the Laplace inversion algorithm.

and decreasing post-injection uplift rate, such that the strain rate and uplift rate reach their maximum at the end of the injection (Figure 8b). These characteristics (i.e., increasing then decreasing uplift rates of ground deformation) have been observed at various volcanic systems, for example, at Long Valley Caldera, Campi Flegrei, and Laguna del Maule (Le Mével et al., 2016). At Laguna del Maule volcanic field in Chile, they are explained as consequences of time-varying injection rates (Le Mével et al., 2016). While time-dependent injection rates driven by magma supply dynamics from deeper reservoirs or mantle plumes are possible (Poland et al., 2012; Bato et al., 2018, e.g.), the combination of injection, pore magma transport, and relaxation in a mushy chamber provides an alternative explanation, following the common practice of assuming constant or exponentially decreasing injection rates (Segall, 2016; Huppert \& Woods, 2002; Biggs \& Pritchard, 2017). Several other mechanisms, such as relaxation of the crust and hydrothermal circulation, can further complicate ground deformation signals, which demand more complex magma chamber deformation models (Segall, 2016; Novoa et al., 2019).

Although the time-dependent features in ground deformation may suggest the existence of a mushy chamber, the magnitude of ground deformation caused by a deforming mushy chamber is limited in its ability to constrain key parameters of the chamber such as its volume, pressure, and likelihood to rupture. Similar to classical models, the depth of the magma chamber $d$ can be straightforwardly obtained from (8) by comparing the vertical and horizontal components of the displacement $d=u_{z} \rho / u_{\rho}$ (Segall, 2019). With $d$ and the elastic properties of crustal rock constrained, the ground deformation further constrains $\sigma_{m}^{r r} V_{0} \propto \Delta V$ (or $P_{l} V_{0}$ if there is no mush, $\Delta V$ is injected volume), but can not constrain pressure/stress and chamber volume individually. We find that when the depth $d$ is fixed, the amplitude of ground deformation $u_{\rho, z} \propto \Delta V \frac{R_{o}^{3}}{r_{o}^{3}}$. Therefore the ground deformation increases with the volume ratio of mush and is independent of the size of the chamber (Figure 9): for the same injection event, a large chamber with $50 \%$ mush and a small chamber with $50 \%$ mush cause the same ground deformation, and 


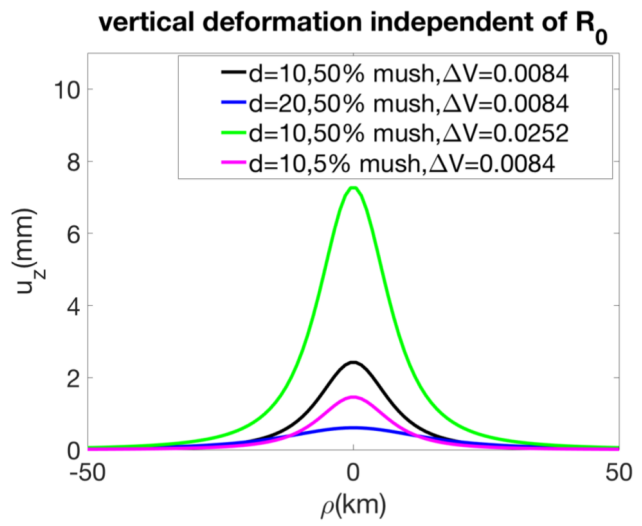

(a)

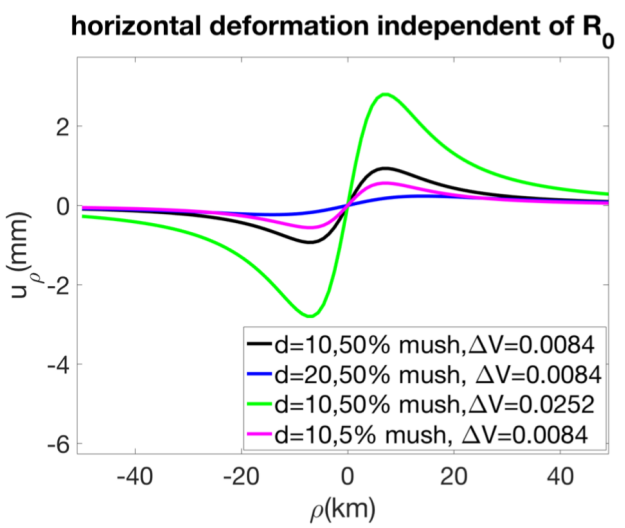

(b)

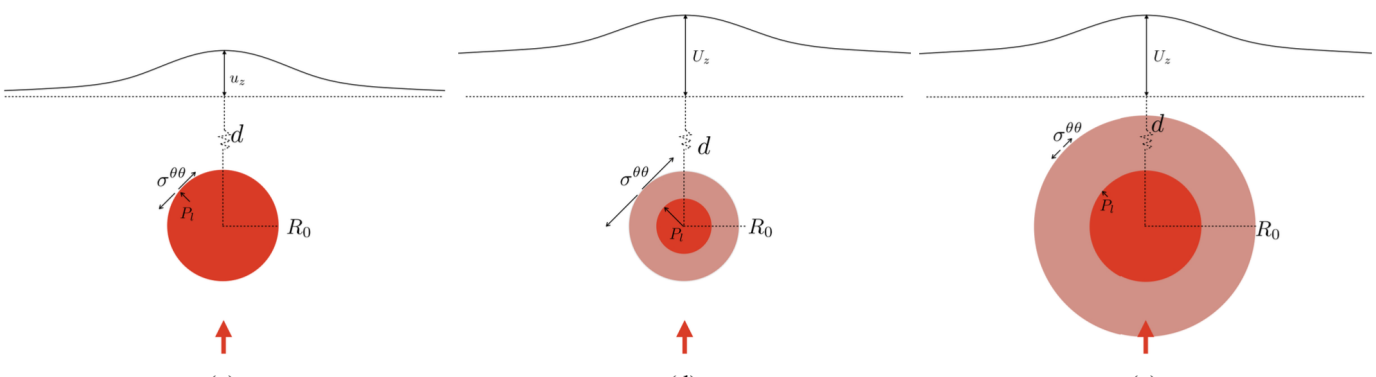

(c)

(d)

(e)

Figure 9. (a) and (b) show vertical and horizontal displacement at the surface for different combination of burial depth $d(\mathrm{~km})$, mush volume fraction, and injected volume $\Delta V\left(\mathrm{~km}^{3}\right)$. The ground deformation increases with mush volume fraction, injected volume $\Delta V$, and decreases with burial depth $d$, but does not vary with the size of the chamber. (c)-(e) are cartoons illustrating three different magma chambers under the same magma injection. Tensile stress, chamber pressure, and ground deformation in the new steady state $(t \rightarrow \infty)$ are shown in all three cases (not to scale). Case (c) represents a liquid chamber with radius $r_{0}$; case (d) represents a mushy chamber with total chamber radius $r_{0}$; case (e) represents a mushy chamber with liquid core radius $r_{0}$. All three chambers are buried at the same depth $d$ and subjected to the same amount of injected magma $\Delta V$. Cases (d) and (e) cause the same ground deformation as they have the same mush volume fraction, but cause different tensile stress and pressure.

that a liquid chamber always causes smaller ground deformation than a mushy chamber, regardless of its size. On the other hand, the pressure and tensile stress depend on both the volume ratio of mush and the total volume of the chamber. Therefore, a small liquid chamber may cause smaller ground elevation compared to a large mushy chamber, but is more likely to erupt due to higher pressure and tensile stress. This non-uniqueness poses a challenge to applying our forward models to interpret ground deformation data. Combining ground deformation data with other geophysical measurements, such as seismic, electromagnetic, and gravimetry measurements, is necessary to provide constraints on the volumes of liquid and mush, and to increase the applicability of models as proposed here (Magee et al., 2018; Ward et al., 2014).

\subsection{Implication on the interpretation of crystal zoning}

One implication of the poroviscoelastic magma chamber model for petrologic interpretations is the potential reversal of melt transport directions to produce chemical 
zonation in phenocrysts via exposing crystals to pore magma with evolving chemical fingerprints (Figure 2, Figure 6b and Figure B2). Chemically zoned phenocrysts are seen as sensitive recorders of magmatic conditions. A variety of processes are linked to zonation including changes in the temperature, composition, pressure, water content, and oxygen fugacity of the host magma (Ruprecht \& Wörner, 2007, e.g.,) or by transport of crystals through gradients in physico-chemical properties in a zoned magma chamber (Ginibre et al., 2002, e.g.,). Whereas simple zonation of a mafic core and more evolved rim (or vice versa) are commonly explained by magma mixing events; more complex zonation, including oscillatory zoning, require similarly complex physical mechanisms (Perugini et al., 2005; Ginibre \& Wörner, 2007). We suggest that complex zonation features could also develop in phenocrysts due to transport of melt in and out of the mush zone. Oscillatory zoning, for example, could form near the melt-mush interface as crystals are washed by outward (e.g., more primitive, hotter) and inward (e.g., less primitive, cooler) melt. Sieve textured phenocrysts might be located further into the mush zone, where only a larger injection event would allow a more primitive melt to encounter the crystals, and which would be less subjected to significant changed in flow direction. In addition to injectioninduced pressure gradients, other processes such as vesiculation and or gas loss may also allow melt transport through the mush producing 'in-phase' zonation. The potential to produce chemical zonation within magmatic mush merits further examination including the physical processes of disaggregating the mush and the probability of incorporating those crystals into the melt (Parmigiani et al., 2014, e.g.,), and the examination of asymmetric zonation patterns (e.g., non-concentric) that might result in a partially interconnected network of crystals.

\subsection{Future studies}

Our current viscoelastic model serves as a foundation for understanding of how mush rheology impacts the first-order mechanical responses of a magmatic reservoir, with assumed simplifications such as isothermal condition, radial symmetry, uniform material properties, and simplified injection time series. As natural volcanic system are more complex, there is room for future refinement of the current model. Theses future studies will yield a more thorough understandings of the role of crystal mush in magmatic reservoirs with more complex features or under more realistic conditions, such as temperature variations, non-uniform material properties, evolving magma-mush boundary undergoing phaseand rheological transitions, volatile exsolution and its effect on mush properties, more complex injection processes and more complex mush/crustal rheologies informed by field and experimental observations (Karlstrom et al., 2012; Poland et al., 2012; Bato et al., 2018; Kiser et al., 2018; Lamy-Chappuis et al., 2020). Better constraints on the properties of crustal magmatic system from improved geophysical observations, and incorporation of more complex features described above, will allow for a more realistic description of the mechanical behaviors of mushy magmatic reservoirs and better interpretations on the observed geodetic and petrologic observations.

Recent studies focusing on the multiphase nature of crustal magmatic systems also shed light on some potentially important physical processes that may be incorporated or combined to our current model. In a recent study by Mittal and Richards (2019), the two-phase nature of the hosting crust of the magma chamber was modeled using similar quantitative methods, with the additional incorporation of a thermal effect (i.e., a thermal-poroviscoelastic description). In this study, gas percolation out of the magma chamber was studied in detail, while the dynamics and deformation of the magma chamber itself was modeled in a simplified fashion (Mittal \& Richards, 2019). Future implementation of our current model with a thermal-poroviscoelastic rheology, combined with a crustal-percolation model similar to Mittal and Richards (2019), could extend the onephase description of the crustal system to a fully two-phase description extending from within the magma chamber to the surface. 
For the purposes of our study, we selected a simple poroviscoelastic rheology. Although the actual rheology of crystal mush is unknown due to experimental limitations, there are several other rheologies that may be useful for describing more complex processes in the mush system, such as viscous compaction, plastic yielding, grain-size evolution, local disequilibrium, and presence of a third phase (McKenzie, 1984; Turcotte \& Morgan, 1992; Dymkova \& Gerya, 2013; Montési \& Zuber, 2002; Bercovici \& Ricard, 2003; Yarushina \& Podladchikov, 2015; Huber \& Parmigiani, 2018). Additionally, different types of models, which treat mush as a discrete granular system, could account for complex microscopic processes such as grain-to-grain and grain-to-fluid interactions (Schleicher et al., 2016; Bergantz et al., 2017; Carrara et al., 2019). Combining these different approaches with the model presented here in future studies could yield insight into the relationship between geodetic observations and the complex processes of mushy magma chambers.

\section{Summary}

In this study, we extend a previous mechanical model by Liao et al. (2018) on mushy magma chambers with poroelastic or viscoelastic mush, by incorporating a more general mush rheology of poroviscoelasticity. We subject the new mushy magma chamber model to an external perturbation of a magma injection with constant injection rate for a duration of time, and observe the similarities and differences caused by different mush rheology on evolution of pressure, stress, magma transport, and surface elevation. We found that the poroviscoelastic mush display both mechanisms of poroviscoelastic diffusion, and viscoelastic relaxation, and that the magma chamber displays features similar to both end members at different stages during its evolution in time. Based on these features, we identify two characteristic timescales that describe the post-injection evolution of the poroviscoelastic mushy chamber: a short-term post-injection time $t_{\text {post }}^{\text {short }}$ and a long-term post-injection time $t_{\text {post }}^{\text {long }}$. Over $t_{\text {post }}^{\text {short }}$, the chamber is dominated by poroelastic diffusion characterized by relatively rapid chamber pressure decrease, crustal tensile increase, and transport (i.e.,leaking) of magma from the fluid region to the mush. $t_{\text {post }}^{l o n g}$ indicates the period dominated by viscoelastic relaxation, which is characterized by relatively slow decrease in chamber pressure, increase in tensile stress, and inverse transport (i.e., leaking-back) of magma from the mush region to the fluid region. The two characteristic timescales are determined by material properties and geometry of the chamber, but the short-term timescale is more sensitive to the poroelastic diffusion time $\tau_{\text {diffusion }}$, and the long-term timescale to the viscoelastic relaxation time $\tau_{\text {relaxation. }}$. The features of the post-injection evolution of a poroviscoelastic chamber indicate that the poroelastic diffusion mechanism, which causes higher rates of chamber deformation and strain, is more likely to be relevant for potential interpretation of surface observations, while the viscoelastic relaxation, which causes drastic change in the magma transport direction, is potentially relevant for interpreting petrological and geochemical evidence of crystal growth.

\section{Acknowledgments}

We thank James Rice for helpful discussions in the early stages of this work, and two anonymous reviewers for reviewing this manuscript. There is no experimental or observational data associated to this study. Codes for realizing the analytical and semi-analytical solutions can be downloaded from https://codeocean.com/capsule/1321571/tree.

\section{References}

Abate, J., \& Whitt, W. ing laplace transforms. 421
(2006). A unified framework for numerically invertINFORMS Journal on Computing, 18(4), 408://doi.org/10.1287/ijoc.1050.0137 doi: 
10.1287/ijoc.1050.0137

Aharonov, E., \& Sparks, D. Phys. Rev. E, 60(6).

Albino, F., Pinel, V., \& Sigmundsson, F. ～(2010). Influence of surface load variations on eruption likelihood: application to two icelandic subglacial volcanoes, grímsvötn and katla. Geophysical journal international, 181(3), 1510-1524.

Antonelli, M. A., Mittal, T., McCarthy, A., Tripoli, B., Watkins, J. M., \& DePaolo, D. J. (2019). Ca isotopes record rapid crystal growth in volcanic and subvolcanic systems. Proceedings of the National Academy of Sciences, 116(41), 20315-20321. Retrieved from https://www.pnas.org/content/116/41/20315 doi: $10.1073 /$ pnas.1908921116

Bachmann, O., \& Bergantz, G. W. (2006). Gas percolation in upper-crustal silicic crystal mushes as a mechanism for upward heat advection and rejuvenation of near-solidus magma bodies. Journal of Volcanology and Geothermal Research, 149(1), 85-102. Retrieved from http://www.sciencedirect.com/ science/article/pii/S0377027305002076 doi: https://doi.org/10.1016/ j.jvolgeores.2005.06.002

Bachmann, O., \& Huber, C. (2016). Silicic magma reservoirs in the earth's crust. American Mineralogist, 101(11), 2377-2404. Retrieved from http://ammin.geoscienceworld.org/content/101/11/2377 doi: 10.2138/am-2016-5675

Bato, M. G., Pinel, V., Yan, Y., Jouanne, F., \& Vandemeulebrouck, J. (2018). Possible deep connection between volcanic systems evidenced by sequential assimilation of geodetic data. Scientific Reports, 8(1), 11702. trieved from https://doi.org/10.1038/s41598-018-29811-x 10.1038/s41598-018-29811-x

Bercovici, D., \& Ricard, Y. $\quad(2003,03)$. Energetics of a two-phase model of lithospheric damage, shear localization and plate-boundary formation. Geophysical Journal International, 152(3), 581-596. Retrieved from http://dx.doi.org/ 10.1046/j.1365-246X.2003.01854.x

Bergantz, G. W., Schleicher, J. M., \& Burgisser, A. (2017). On the kinematics and dynamics of crystal-rich systems. Journal of Geophysical Research: Solid Earth, 122(8), 6131-6159. Retrieved from https://agupubs.onlinelibrary .wiley.com/doi/abs/10.1002/2017JB014218 doi: 10.1002/2017JB014218

Biggs, J., \& Pritchard, M. E. (2017). Global volcano monitoring: what does it mean when volcanoes deform? Elements, 13(1), 17-22.

Biot, M. A. (1941). General theory of three-dimensional consolidation. Journal of applied physics, 12 .

Biot, M. A. (1962). Mechanics of deformation and acoustic propagation in porous media. Journal of Applied Physics, 33(4), 1482-1498. Retrieved from https:// doi.org/10.1063/1.1728759 doi: 10.1063/1.1728759

Carrara, A., Burgisser, A., \& Bergantz, G. W. (2019). Lubrication effects on magmatic mush dynamics. search, 380, 19 - 30 .

Journal of Volcanology and Geothermal ReRetrieved from http://www.sciencedirect.com/ j.jvolgeores.2019.05.008

Cashman, K. V., Sparks, R. S. J., \& Blundy, J. D. ～(2017). Vertically extensive and unstable magmatic systems: A unified view of igneous processes. Science, 355(6331). Retrieved from http://science.sciencemag.org/content/355/ 6331/eaag3055 doi: 10.1126/science.aag3055

Cheadle, M., Elliott, M., \& McKenzie, D. (2004). Percolation threshold and permeability of crystallizing igneous rocks: The importance of textural equilibrium. Geology, 32(9), 757-760.

Cheng, A. H.-D. (2016). Poroelasticity. Springer International Publishing. doi: doi .org/10.1007/978-3-319-25202-5 
Cooper, K. M. (2019). Time scales and temperatures of crystal storage in magma reservoirs: implications for magma reservoir dynamics. Philosophical Transactions of the Royal Society A: Mathematical, Physical and Engineering Sciences, 377(2139), 20180009. Retrieved from https:// royalsocietypublishing.org/doi/abs/10.1098/rsta.2018.0009 doi: $10.1098 /$ rsta.2018.0009

Costa, F., Shea, T., \& Ubide, T. (2020). Diffusion chronometry and the timescales of magmatic processes. Nature Reviews Earth \& Environment, 1 (4), 201-214. Retrieved from https://doi.org/10.1038/s43017-020-0038-x doi: 10.1038/ s43017-020-0038-x

Currenti, G., \& Williams, C. A. (2014). Numerical modeling of deformation and stress fields around a magma chamber: Constraints on failure conditions and rheology. Physics of the Earth and Planetary Interiors, 226, 14-27.

Dragoni, M., \& Magnanensi, C. (1989). Displacement and stress produced by a pressurized, spherical magma chamber, surrounded by a viscoelastic shell. Physics of the Earth and Planetary Interiors, 56(3), 316 - 328. Retrieved from http://www.sciencedirect.com/science/article/pii/0031920189901660 doi: http://dx.doi.org/10.1016/0031-9201(89)90166-0

Dymkova, D., \& Gerya, T. (2013). Porous fluid flow enables oceanic subduction initiation on earth. Geophysical Research Letters, 40(21), 5671-5676.

Gerbault, M., Hassani, R., Novoa Lizama, C., \& Souche, A. (2018). Threedimensional failure patterns around an inflating magmatic chamber. Geochemistry, Geophysics, Geosystems, 19(3), 749-771. Retrieved from https:// agupubs.onlinelibrary.wiley.com/doi/abs/10.1002/2017GC007174 doi: https://doi.org/10.1002/2017GC007174

Ginibre, C., \& Wörner, G. (2007). Variable parent magmas and recharge regimes of the parinacota magma system (n. chile) revealed by fe, mg and sr zoning in plagioclase. Lithos, 98(1-4), 118-140.

Ginibre, C., Wörner, G., \& Kronz, A. (2002). Minor-and trace-element zoning in plagioclase: implications for magma chamber processes at parinacota volcano, northern chile. Contributions to Mineralogy and Petrology, 143(3), 300-315.

Grosfils, E. B. (2007). Magma reservoir failure on the terrestrial planets: Assessing the importance of gravitational loading in simple elastic models. Journal of Volcanology and Geothermal Research, $166(2)$.

Gudmundsson, A. (2012). Magma chambers: Formation, local stresses, excess pressures, and compartments. Journal of Volcanology and Geothermal Research, 237-238(Supplement C), 19 - $41 . \quad$ Retrieved from http:// wWw.sciencedirect.com/science/article/pii/S0377027312001539 doi: https://doi.org/10.1016/j.jvolgeores.2012.05.015

Gudmundsson, A. (2016). The mechanics of large volcanic eruptions. Earth-Science Reviews, 163. doi: 10.1016/j.earscirev.2016.10.003

Huber, C., Bachmann, O., \& Dufek, J. (2011). Thermo-mechanical reactivation of locked crystal mushes: Melting-induced internal fracturing and assimilation processes in magmas. $\quad$ Earth and Planetary Science Letters, $304(3-4), 443$ 454. Retrieved from http://www.sciencedirect.com/science/article/pii/ S0012821X11000938 doi: https://doi.org/10.1016/j.epsl.2011.02.022

Huber, C., \& Parmigiani, A. (2018). A physical model for three-phase compaction in silicic magma reservoirs. Journal of Geophysical Research: Solid Earth, 123(4), 2685-2705. Retrieved from https://agupubs.onlinelibrary .wiley.com/doi/abs/10.1002/2017JB015224 doi: https://doi.org/10.1002/ 2017JB015224

Huppert, H. E., \& Woods, A. W. $\quad(2002,12$ 05). The role of volatiles in magma chamber dynamics. Nature, 420(6915), 493-495. Retrieved from http://dx .doi.org/10.1038/nature01211

Jellinek, A. M., \& DePaolo, D. J. (2003, Jul 01). A model for the origin of large sili- 
cic magma chambers: precursors of caldera-forming eruptions. Bulletin of Volcanology, 65(5), 363-381. Retrieved from https://doi.org/10.1007/s00445 -003-0277-y doi: 10.1007/s00445-003-0277-y

Karlstrom, L., Dufek, J., \& Manga, M. (2010). Magma chamber stability in arc and continental crust. Journal of Volcanology and Geothermal Research, 190(3), $249-270 . \quad$ Retrieved from http://www.sciencedirect.com/ science/article/pii/S0377027309003977 doi: https://doi.org/10.1016/ j.jvolgeores.2009.10.003

Karlstrom, L., Rudolph, M. L., \& Manga, M. (2012). Caldera size modulated by the yield stress within a crystal-rich magma reservoir. Nature Geoscience, 5(6), 402-405. Retrieved from https://doi.org/10.1038/ngeo1453 doi: $10.1038 /$ ngeo1453

Kiser, E., Levander, A., Zelt, C., Schmandt, B., \& Hansen, S. ～(2018). Focusing of melt near the top of the mount st. helens (usa) magma reservoir and its relationship to major volcanic eruptions. Geology, 46(9), 775-778.

Lamy-Chappuis, B., Heinrich, C. A., Driesner, T., \& Weis, P. (2020). Mechanisms and patterns of magmatic fluid transport in cooling hydrous intru-

sions. $\quad$ Earth and Planetary Science Letters, 535, 116111. Retrieved from http://www.sciencedirect.com/science/article/pii/S0012821X20300546 doi: https://doi.org/10.1016/j.epsl.2020.116111

Le Mével, H., Feigl, K. L., Córdova, L., DeMets, C., \& Lundgren, P. (2015). Evolution of unrest at laguna del maule volcanic field (chile) from insar and gps measurements, 2003 to 2014 . Geophysical Research Letters, 42(16), 65906598. Retrieved from https://agupubs.onlinelibrary.wiley.com/doi/abs/ 10.1002/2015GL064665 doi: 10.1002/2015GL064665

Le Mével, H., Gregg, P. M., \& Feigl, K. L. $\quad$ (2016, 08). Magma injection into a long-lived reservoir to explain geodetically measured uplift: Application to the 2007-2014 unrest episode at laguna del maule volcanic field, chile. Journal of Geophysical Research. Solid Earth, 121(8), 6092-6108. Retrieved from http://www.ncbi.nlm.nih.gov/pmc/articles/PMC5101856/ doi: 10.1002/2016JB013066

Liao, Y., Soule, S. A., \& Jones, M. (2018, 2019/03/11). On the mechanical effects of poroelastic crystal mush in classical magma chamber models. Journal of Geophysical Research: Solid Earth, 123(11), 9376-9406. Retrieved from https:// doi.org/10.1029/2018JB015985 doi: 10.1029/2018JB015985

Magee, C., Stevenson, C. T., Ebmeier, S. K., Keir, D., Hammond, J. O., Gottsmann, J. H., .. Petronis, M. S. (2018). Magma plumbing systems: a geophysical perspective. Journal of Petrology, 59(6), 1217-1251.

Makhnenko, R. Y., \& Labuz, J. F. (2016). Elastic and inelastic deformation of fluidsaturated rock. Philosophical Transactions of the Royal Society A: Mathematical, Physical and Engineering Sciences, 374(2078), 20150422. Retrieved from https://royalsocietypublishing.org/doi/abs/10.1098/rsta. 2015.0422 doi: $10.1098 /$ rsta.2015.0422

Marsh, B. D. (1989). Magma chambers. Annual Review of Earth and Planetary Sciences, 17(1), 439-472. doi: 10.1146/annurev.ea.17.050189.002255

Marsh, B. D. (2013). On some fundamentals of igneous petrology. Contributions to Mineralogy and Petrology, 166(3), 665-690.

McKenzie, D. (1984). The generation and compaction of partially molten rock. Journal of petrology, 25(3), 713-765.

McKenzie, D. (2011, 05). Compaction and crystallization in magma chambers: Towards a model of the skaergaard intrusion. Journal of Petrology, 52(5), 905930. Retrieved from http://dx.doi.org/10.1093/petrology/egr009

McTigue, D. F. (1987). Elastic stress and deformation near a finite spherical magma body: Resolution of the point source paradox. Journal of Geophysical Research: Solid Earth, 92(B12), 12931-12940. Retrieved from http:// 
dx.doi.org/10.1029/JB092iB12p12931 doi: 10.1029/JB092iB12p12931

Mittal, T., \& Richards, M. A. (2019). Volatile degassing from magma chambers as a control on volcanic eruptions. Journal of Geophysical Research: Solid Earth, 124(8), 7869-7901. Retrieved from https://agupubs.onlinelibrary.wiley .com/doi/abs/10.1029/2018JB016983 doi: 10.1029/2018JB016983

Montési, L. G., \& Zuber, M. T. (2002). A unified description of localization for application to large-scale tectonics. Journal of Geophysical Research: Solid Earth, 107 (B3), 1-21.

Novoa, C., Remy, D., Gerbault, M., Baez, J., Tassara, A., Cordova, L., .. . Delgado, F. (2019). Viscoelastic relaxation: A mechanism to explain the decennial large surface displacements at the laguna del maule silicic volcanic complex. Earth and Planetary Science Letters, 521, 46-59 0012-821X.

Parmigiani, A., Huber, C., \& Bachmann, O. (2014). Mush microphysics and the reactivation of crystal-rich magma reservoirs. Journal of Geophysical Research: Solid Earth, 119 (8), 6308-6322.

Perugini, D., Poli, G., \& Valentini, L. (2005, Jun 01). Strange attractors in plagioclase oscillatory zoning: petrological implications. Contributions to Mineralogy and Petrology, 149(4), 482-497. Retrieved from https://doi.org/10.1007/ s00410-005-0667-6 doi: 10.1007/s00410-005-0667-6

Pinel, V., \& Jaupart, C. (2003). Magma chamber behavior beneath a volcanic edifice. Journal of Geophysical Research: Solid Earth, 108.

Poland, M. P., Miklius, A., Sutton, A. J., \& Thornber, C. R. (2012). A mantledriven surge in magma supply to kīlauea volcano during 2003-2007. Nature Geoscience, 5(4), 295-300.

Pritchard, M., De Silva, S., Michelfelder, G., Zandt, G., McNutt, S. R., Gottsmann, J., ... Finnegan, N. (2018). Synthesis: Plutons: Investigating the relationship between pluton growth and volcanism in the central andes. Geosphere, $14(3)$, 954-982.

Rummel, L., Kaus, B. J., Baumann, T. S., White, R. W., \& Riel, N. (2020). Insights into the compositional evolution of crustal magmatic systems from coupled petrological-geodynamical models. Journal of Petrology, 61.

Ruprecht, P., \& Wörner, G. (2007). Variable regimes in magma systems documented in plagioclase zoning patterns: El misti stratovolcano and andahua monogenetic cones. Journal of Volcanology and Geothermal Research, 165(3-4), 142-162.

Schleicher, J. M., \& Bergantz, G. W. (2017, 06). The mechanics and temporal evolution of an open-system magmatic intrusion into a crystal-rich magma. Journal of Petrology, 58(6), 1059-1072. Retrieved from http://dx.doi.org/10.1093/ petrology/egx045

Schleicher, J. M., Bergantz, G. W., Breidenthal, R. E., \& Burgisser, A. (2016). Time scales of crystal mixing in magma mushes. Geophysical Research Letters, 43(4), 1543-1550. Retrieved from https://agupubs.onlinelibrary.wiley .com/doi/abs/10.1002/2015GL067372 doi: 10.1002/2015GL067372

Schmeling, H. (1985). Numerical models on the influence of partial melt on elastic, anelastic and electric properties of rocks. part i: elasticity and anelasticity.

Physics of the Earth and Planetary Interiors, 41(1), 34 - 57. Retrieved from http://www.sciencedirect.com/science/article/pii/0031920185901001 doi: https://doi.org/10.1016/0031-9201(85)90100-1

Schmeling, H., Kruse, J. P., \& Richard, G. (2012). Effective shear and bulk viscosity of partially molten rock based on elastic moduli theory of a fluid filled poroelastic medium. Geophysical Journal International, 190(3), 1571-1578. Retrieved from https://onlinelibrary.wiley.com/doi/abs/10.1111/j.1365 -246X.2012.05596.x doi: https://doi.org/10.1111/j.1365-246X.2012.05596.x

Segall, P. (2016). Repressurization following eruption from a magma chamber with a viscoelastic aureole. Journal of Geophysical Research: Solid Earth, 121(12), 
8501-8522. Retrieved from http://dx.doi.org/10.1002/2016JB013597 (2016JB013597) doi: 10.1002/2016JB013597

Segall, P. (2019). Magma chambers: what we can, and cannot, learn from volcano geodesy. Philosophical Transactions of the Royal Society A: Mathematical, Physical and Engineering Sciences, 377(2139), 20180158. Retrieved from https://royalsocietypublishing.org/doi/abs/10.1098/rsta.2018.0158 doi: $10.1098 /$ rsta.2018.0158

Shaw, H., Wright, T., Peck, D., \& Okamura, R. (1968). The viscosity of basaltic magma; an analysis of field measurements in makaopuhi lava lake, hawaii. American Journal of Science, 266(4), 225-264.

Singer, B. S., Le Mével, H., Licciardi, J. M., Córdova, L., Tikoff, B., Garibaldi, N., ... Feigl, K. L. (2018). Geomorphic expression of rapid holocene silicic magma reservoir growth beneath laguna del maule, chile. Science Advances, 4 (6). Retrieved from http://advances.sciencemag.org/content/4/6/eaat1513 doi: 10.1126/sciadv.aat1513

Sparks, R. S. J., \& Cashman, K. V. (2017). Dynamic magma systems: Implications for forecasting volcanic activity. Elements, 13(1), 35-40. Retrieved from http://elements.geoscienceworld.org/content/13/1/35 doi: 10.2113/gselements.13.1.35

Spera, F. J., \& Bohrson, W. A. (2018). Rejuvenation of crustal magma mush: A tale of multiply nested processes and timescales. American Journal of Science, 318(1), 90-140. Retrieved from https://www.ajsonline.org/content/318/ 1/90 doi: $10.2475 / 01.2018 .05$

Turcotte, D. L., \& Morgan, J. P. (1992). The physics of magma migration and mantle flow beneath a mid-ocean ridge. Mantle Flow and Melt Generation at MidOcean Ridges, 71, 155-182.

Ward, K. M., Zandt, G., Beck, S. L., Christensen, D. H., \& McFarlin, H. (2014). Seismic imaging of the magmatic underpinnings beneath the altiplano-puna volcanic complex from the joint inversion of surface wave dispersion and receiver functions. Earth and Planetary Science Letters, 404, 43-53.

Wieser, P. E., Edmonds, M., Maclennan, J., \& Wheeler, J. (2020). Microstructural constraints on magmatic mushes under kīlauea volcano, hawaii. Nature Communications, 11(1), 14. Retrieved from https://doi.org/10.1038/ s41467-019-13635-y doi: 10.1038/s41467-019-13635-y

Yarushina, V. M., \& Podladchikov, Y. Y. (2015). (de)compaction of porous viscoelastoplastic media: Model formulation. Journal of Geophysical Research: Solid Earth, 120(6), 4146-4170. Retrieved from https:// agupubs.onlinelibrary.wiley.com/doi/abs/10.1002/2014JB011258 doi: 10.1002/2014JB011258

Zhan, Y., \& Gregg, P. (2019). How accurately can we model magma reservoir failure with uncertainties in host rock rheology? Journal of Geophysical Research: Solid Earth.

\section{Appendix A Governing equations and solution method}

The quantitative treatment of the equations of motions and boundary conditions follows closely (Liao et al., 2018). Specifically, we could obtain the poroviscoelastic solutions by transforming the poroelastic solutions in (Liao et al., 2018) under correspondence principle. The poroviscoelastic rheology can be alternatively expressed using Laplace transform

$$
\begin{aligned}
& \widetilde{\boldsymbol{\sigma}_{m}}=\left(K_{m}-\frac{2}{3} \overline{\mu_{m}}\right) \nabla \cdot \widetilde{\vec{u}_{m}} \boldsymbol{I}+\overline{\mu_{m}}\left(\nabla \widetilde{\vec{u}_{m}}+\nabla{\widetilde{\overrightarrow{u_{m}}}}^{T}\right)-\alpha \widetilde{P_{f}} \boldsymbol{I} \\
& \widetilde{m}=\rho_{f} \alpha\left(\nabla \cdot \widetilde{\vec{u}_{m}}+\frac{\alpha}{K_{u}-K_{m}} \widetilde{P_{f}}\right)
\end{aligned}
$$


Table A1. principle notations

\begin{tabular}{lc}
\hline symbol & definition \\
\hline $\boldsymbol{\sigma}_{m}$ & stress for crystal mush \\
$\boldsymbol{\epsilon}_{m}$ & strain for crystal mush \\
$\overrightarrow{u_{m}}$ & displacement for crystal mush \\
$\vec{q}$ & Darcy velocity \\
$P_{l}$ & magma pressure in liquid core \\
$P_{f}$ & pore pressure \\
$m$ & variation of fluid content \\
$M_{\text {leak }}$ & mass of magma transported into mush \\
$M_{\text {inj }}$ & mass of magma injected \\
$\kappa$ & permeability of mush \\
$\eta_{f}$ & pore magma viscosity \\
$K_{l}$ & bulk modulus of core magma \\
$M_{o}$ & initial mass of core magma \\
$\mu_{m}$ & shear modulus of mush \\
$\eta_{m}$ & shear viscosity of mush \\
$K_{m}$ & drained bulk modulus of mush \\
$\alpha$ & Biot coefficient of mush \\
$u_{\rho}$ & horizontal displacement of the surface \\
$u_{z}$ & vertical displacement of the surface \\
$\mu_{r}$ & shear modulus of the crust \\
$\nu$ & Poisson's ratio of the crust \\
\hline
\end{tabular}

where the Laplace transform is defined as $\widetilde{f(r, s)} \equiv \int_{0}^{\infty} f(r, t) e^{-s t} \mathrm{dt}$. The effect of viscous relaxation is reflected by a rigidity that varies with time (i.e., function of $s$ under Laplace transform)

$$
\widetilde{\mu_{m}}=\mu_{m} \frac{\eta_{m} s}{\eta_{m} s+\mu_{m}}
$$

From the equilibrium condition $\nabla \cdot \widetilde{\boldsymbol{\sigma}}=0 \rightarrow \nabla\left(\left(K_{m}+\frac{4}{3} \overline{\mu_{m}}\right) \nabla \cdot \widetilde{\vec{u}}-\alpha \widetilde{P_{f}}\right)=0$, we can define time-dependent function $\zeta(t)$ such that its Laplace transform

$$
\widetilde{\zeta}(s)=\left(K_{m}+\frac{4}{3} \overline{\mu_{m}}\right) \nabla \cdot \widetilde{\vec{u}}-\alpha \widetilde{P_{f}}
$$

Following steps in (Liao et al., 2018) and non-dimensionelize the system by length scale $R_{o}$ (chamber radius), time scale $\eta_{m} / \mu_{m}$ (relaxation time) and stress/pressure scale $\mu_{r}$ (rock rigidity), the boundary values have the relation

$$
\begin{aligned}
& \widetilde{P_{f}}\left(\frac{r_{o}}{R_{o}}\right)=\overline{a_{1}} \widetilde{m}\left(\frac{r_{o}}{R_{o}}\right)+\overline{a_{2}} \widetilde{\zeta} \\
& \widetilde{u_{m}}\left(\frac{r_{o}}{R_{o}}\right)=\overline{b_{1}} \int_{\frac{r_{o}}{R_{o}}}^{1} r^{\prime 2} \widetilde{m}\left(r^{\prime}\right) \mathrm{d} r^{\prime}+\overline{b_{2}} \widetilde{\zeta}+\widetilde{u_{m}}(1) \frac{R_{o}^{2}}{r_{o}^{2}} \\
& \widetilde{\sigma_{m}^{r} r}\left(\frac{r_{o}}{R_{o}}\right)=\overline{c_{1}} \int_{\frac{r_{o}}{R_{o}}}^{1} r^{\prime 2} \widetilde{m}\left(r^{\prime}\right) \mathrm{d} r^{\prime}+\overline{c_{2}} \widetilde{\zeta}+\overline{c_{3}} \widetilde{u_{m}}(1) \\
& \widetilde{\sigma_{m}^{r r}}(1)=\widetilde{\zeta}-4 \frac{\overline{\mu_{m}}}{\mu_{r}} \widetilde{u_{m}}(1) \\
& \widetilde{P_{l}}=\overline{d_{1}} \int_{\frac{r_{o}}{R_{o}}}^{1} r^{2} \widetilde{m}(r) \mathrm{d} r+\overline{d_{2}} \widetilde{\zeta}-\frac{3 K_{l} R_{o}^{3}}{\mu_{r} r_{o}^{3}} \widetilde{u_{m}}(1)+\overline{f_{4}}
\end{aligned}
$$


where $\overline{f_{4}}=\frac{K_{l}}{\mu_{r}} \frac{\Delta M}{M_{o}} \frac{1}{s}$ (for instantaneous injection) or $\overline{f_{4}}=\frac{K_{l}}{\mu_{r}} \frac{\Delta M}{M_{o}} \frac{1-e^{s t_{i n j}}}{s^{2} t_{i n j}}$ (for gradual injection), and the $s$-dependent coefficients $\overline{a_{1}}, \overline{a_{2}}, \overline{b_{1}}, \overline{b_{2}}, \overline{c_{1}}, \overline{c_{2}}, \overline{d_{1}}, \overline{d_{2}}$ have the same forms as those defined in Appendix A.2.4 in (Liao et al., 2018) while substituting $\bar{\mu}(s)$ for mush rigidity. Substituting (A2) into the boundary conditions and into Darcy's law, mass conservation, and equilibrium condition, we obtain (dimensionless) constraint on the fluid content $\widetilde{m}$

$$
\nabla^{2} \widetilde{m}-\frac{\tau_{\text {diffusion }}}{\tau_{\text {relaxation }}} \frac{s\left(s+\frac{K_{u}}{K_{u}+\frac{4}{3} \mu_{m}^{o}}\right)}{\left(s+\frac{K_{m}}{K_{m}+\frac{4}{3} \mu_{m}^{o}}\right)} \widetilde{m}=0
$$

and the boundary conditions

$$
\frac{\partial \widetilde{m}}{\partial r}(r=1)=0, \quad \widetilde{a_{1}} \widetilde{m}\left(\frac{r_{o}}{R_{o}}\right)+\overline{h_{o}} \int \widetilde{m} r^{2} d r=\overline{h 1}
$$

where $\overline{h_{0}}$ and $\overline{h_{1}}$ have the same form of $h_{0}$ and $h_{1}$ in $\S$ A.2.4 in (Liao et al., 2018) with $\mu_{m} \rightarrow \overline{\mu_{m}}$. Solving (A3) with the boundary conditions and using the relations between $m, \vec{u}$ and $P_{f}$ similar to those in (Liao et al., 2018), we can find the solutions for $\widetilde{m}$

$$
\widetilde{m}=\frac{A e^{r \sqrt{S_{o}}}}{\sqrt{S_{o}} r}+\frac{B e^{-r \sqrt{S_{o}}}}{\sqrt{S_{o}} r}
$$

with

$S_{o}=\frac{\tau_{\text {diffusion }}}{\tau_{\text {relaxation }}} \frac{s\left(s+\frac{K_{u}}{K_{u}+\frac{4}{3} \mu_{m}^{o}}\right)}{\left(s+\frac{K_{m}}{K_{m}+\frac{4}{3} \mu_{m}^{o}}\right)}, \quad A=\frac{\widetilde{h_{1}} S_{o}^{\frac{3}{2}}\left(\sqrt{S_{o}}+1\right) e^{-\sqrt{S_{o}}}}{2 \bar{g}}, \quad B=\frac{\widetilde{h_{1}} S_{o}^{\frac{3}{2}}\left(\sqrt{S_{o}}-1\right) e^{\sqrt{S_{o}}}}{2 \bar{g}}$

$\bar{g}=\sqrt{S_{o}}\left(\frac{\overline{a_{1}} R_{o}}{r_{o}} S_{o}+\overline{h_{0}}\left(1-\frac{r_{o}}{R_{o}}\right)\right) \cosh \left(\sqrt{S_{o}}\left(1-\frac{r_{o}}{R_{o}}\right)\right)+\left(\left(\overline{h_{0}} \frac{r_{o}}{R_{o}}-\frac{\overline{a_{1}} R_{o}}{r_{o}}\right) S_{o}-\overline{h_{0}}\right) \sinh \left(\sqrt{S_{o}}\left(1-\frac{r_{o}}{R_{o}}\right)\right.$

The Laplace transform of other quantities can all be obtained via (A4), such as core pressure, rock tensile stress and radial stress at the chamber's wall

$$
\begin{aligned}
& \widetilde{\sigma_{\text {rock }}^{\theta \theta}}(1)=-2 \frac{\overline{f_{4}}}{\overline{g_{2}}}-2 \frac{\overline{g_{1}}}{\overline{g_{2}}} \int_{\frac{r_{o}}{R_{o}}}^{1} \tilde{m} r^{2} d r \\
& \widetilde{\sigma_{m}^{r r}}(1)=\widetilde{\sigma_{\text {rock }}^{r r}}(1)=-2 \widetilde{\sigma_{\text {rock }}^{\theta \theta}}(1) \\
& \widetilde{\zeta}=2\left(4 \frac{\overline{\mu_{m}}}{\mu_{r}}-1\right) \widetilde{\sigma^{\theta \theta}} \\
& \widetilde{P}_{l}=\overline{a_{1}} \widetilde{m}\left(\frac{r_{o}}{R_{o}}\right)+\overline{a_{2}} \widetilde{\zeta}
\end{aligned}
$$

Following (McTigue, 1987), we apply a first order correction to obtain surface deformation. The pressure-stress coupling in (McTigue, 1987) is here replaced by a stress-stress coupling at the chamber-crust interface, and the radial component of poroviscoelastic stress plays the role of a virtual pressure in the chamber, leading to the surface deformation (McTigue, 1987; Segall, 2016)

$$
\begin{aligned}
& \widetilde{u_{z}}(\rho, 0)=-\widetilde{\sigma_{m}^{r r}}(1) \frac{d}{R_{0}}\left(\frac{R_{0}}{d}\right)^{3} \frac{1-\nu}{\left(\frac{\rho^{2}}{d^{2}}+1\right)^{\frac{3}{2}}} \\
& \widetilde{u_{\rho}}(\rho, 0)=-\widetilde{\sigma_{m}^{r r}}(1) \frac{\rho}{R_{0}}\left(\frac{R_{0}}{d}\right)^{3} \frac{1-\nu}{\left(\frac{\rho^{2}}{d^{2}}+1\right)^{\frac{3}{2}}}
\end{aligned}
$$

where $u_{z}$ and $u_{\rho}$ are vertical and horizontal displacement on the surface (normalized by chamber radius $R_{0}$ ) measured at distance $\rho$ from the center of the chamber's projection, 


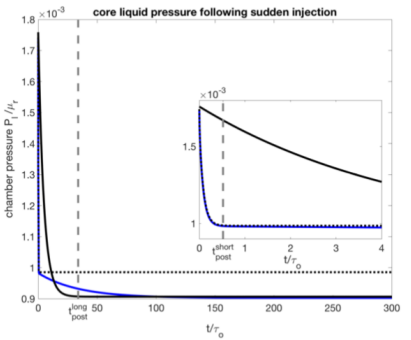

(a)

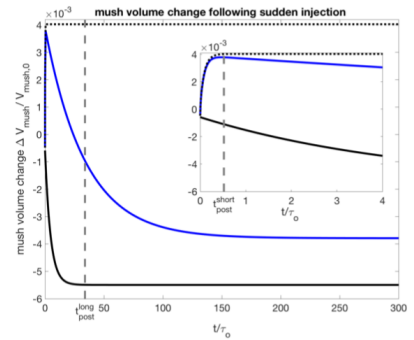

(b)

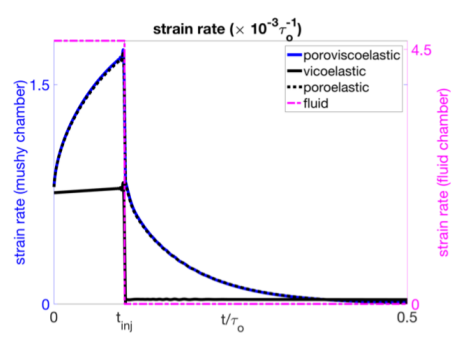

(c)

Figure B1. Panel (a) and (b): post-injection short-term and long-term evolution for core pressure and mushy deformation for three cases (poroviscoelastic, poroelastic, and viscoelastic). Inset panels are zoom-in of the beginning period of the evolution, and grey broken lines indicate the two post-injection timescales $t_{\text {post }}^{\text {long }}$ and $t_{\text {post }}^{\text {short }}$. Panel (c): tensile strain rate $\dot{\epsilon}^{\theta \theta}=\dot{u}\left(R_{o}\right) / R_{o}$ at the wall of the chamber during and after the injection, for four different cases. For mushy chamber, the strain rate is highest at the end of the injection, and remains positive during shortterm post-injection evolution. During long-term post-injection evolution, the strain rate becomes indiscernible.

$\nu$ is Poisson's ratio of the elastic crust. We numerically invert the Laplace solutions to obtain solutions using a matlab code shared on Mathworks File Exchange, which is based on the scheme proposed in (Abate \& Whitt, 2006). The Laplace solution allows us to define the longest timescale in the system. Similar to (Liao et al., 2018), the Laplace solutions can be inverted using the Mellin inversion formula, which yields the solutions in real space as a superposition of exponentially decaying terms in the form of

$$
A(r, t)=A_{0}(r)+A_{1}(r) e^{-t / \tau_{1}}+A_{2}(r) e^{-t / \tau_{2}}+\ldots
$$

where $\tau_{1}$ is the largest decay period, and can be solved graphically given the parameters of the system. We use this timescale to determine the longest timescale in the system's post-injection evolution $t_{\text {post }}^{\text {long }}$ (Liao et al., 2018).

\section{Appendix B Additional model results}




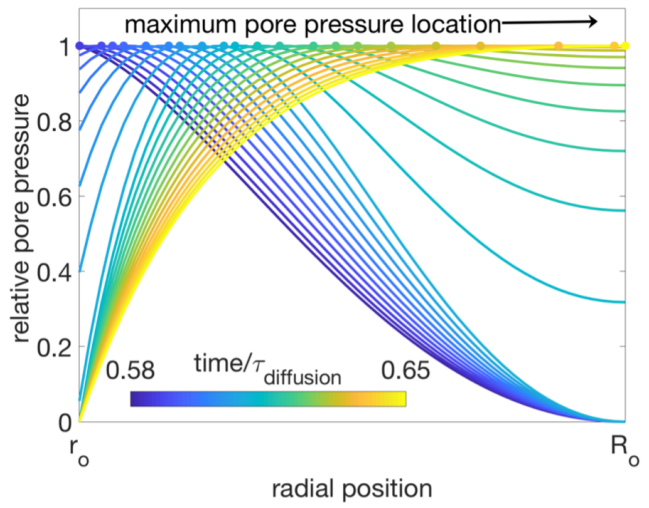

(a)

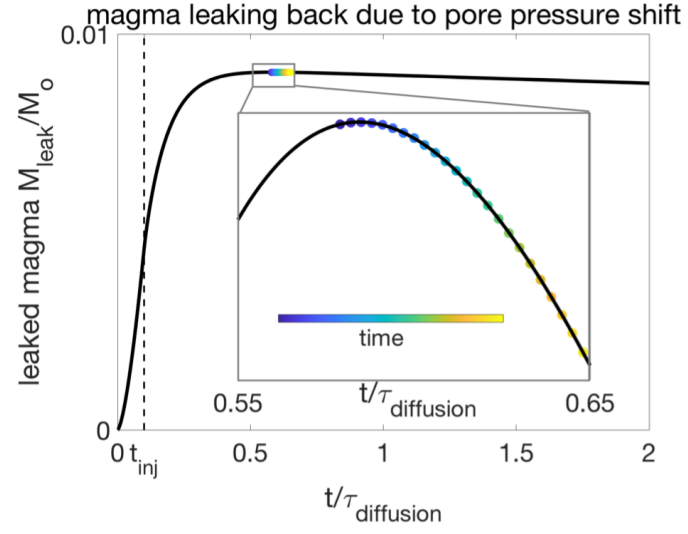

(b)

Figure B2. Panel (a) cumulative amount of leaked magma $M_{l e a k}$ as a function of time during and after the injection. Panel (b) shows the the relative pore pressure $\frac{P_{f}-\min \left(P_{f}\right)}{\max \left(P_{f}\right)-\min \left(P_{f}\right)}$ as function of radial position in the mush shell. Colored lines in (b) correspond to colored data points in (a). The decrease in $M_{\text {leak }}$ with time corresponds to the shift of maximum pore pressure from the inner boundary of the much outwards.

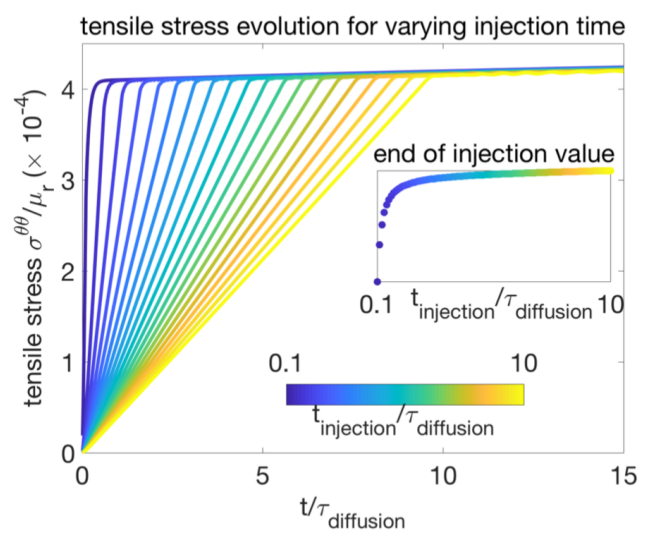

(a)

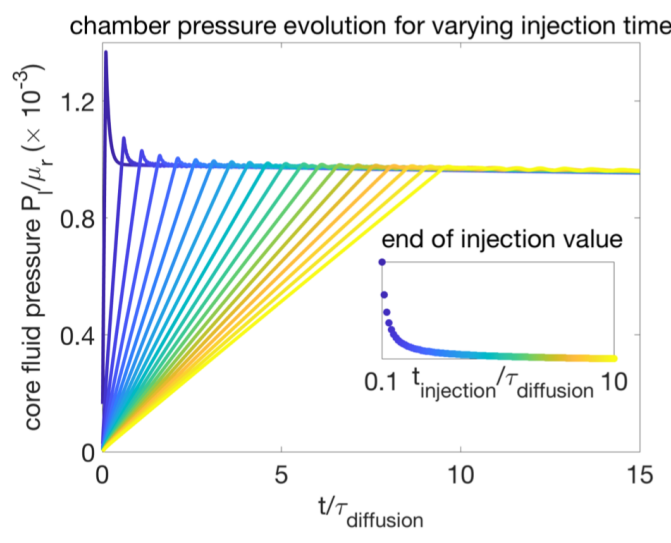

(b)

Figure B3. Evolution of core pressure and tensile stress with time for varying injection time length $t_{i n j}$. The system has $\tau_{\text {diffusion }}=\tau_{\text {relaxation. }}$. Insets show the values at the end of the injection. As $t_{i n j}$ increases, the short-term evolution period shortens and become less apparent. 